\title{
CBP [Task 12] Experimental Study of the Concrete /Saltstone Two-Layer System
}

\section{Cementitious Barriers Partnership}

\author{
November 2016
}

CBP-TR-2015-015, Rev. 1 


\title{
CEMENTITIOUS BARRIERS PARTNERSHIP TASK 12 - EXPERIMENTAL STUDY
}

\author{
Experimental study of the concrete/saltstone \\ 2-layer system
}

\author{
Yannick Protière, M.Sc., jr. eng. \\ Eric Samson, Ph.D., eng. \\ SIMCO Technologies, Inc. \\ Québec, Canada
}

November 2016 


\section{ACKNOWLEDGEMENTS}

This report was prepared for the United States Department of Energy under the Savannah River National Laboratory Cooperative Research and Development Agreement (CRADA) No. CR-08-001. The Cementitious Barriers Partnership is sponsored by the U.S. DOE Office of Tank Waste Management in collaboration with the U. S. NRC and administered through Savannah River National Laboratory CRADA. Reference herein to any specific commercial product, process, or service by trademark, name, manufacturer, or otherwise does not necessarily constitute or imply endorsement, recommendation, or favoring of same by Savannah River Nuclear Solutions, Vanderbilt University or by the United States Government or any agency thereof. The views and opinions of the authors expressed herein do not necessarily state or reflect those of the United States Government or any agency thereof. This report is part of a larger multi-investigator project supported by the $\mathrm{U}$. S. Department of Energy entitled the Cementitious Barriers Partnership. The opinions, findings, conclusions, or recommendations expressed herein are those of the authors and do not necessarily represent the views of the U.S. Department of Energy. This work was also partially supported by the National Institute of Standards and Technology Sustainable, High Performance Infrastructure Materials program.

\section{DISCLAIMER}

This work was prepared under an agreement with and funded by the U. S. Government. Neither the U.S. Government or its employees, nor any of its contractors, subcontractors or their employees, makes any express or implied: 1. warranty or assumes any legal liability for the accuracy, completeness, or for the use or results of such use of any information, product, or process disclosed; or 2. representation that such use or results of such use would not infringe privately owned rights; or 3. endorsement or recommendation of any specifically identified commercial product, process, or service. Any views and opinions of authors expressed in this work do not necessarily state or reflect those of the United States Government, or its contractors, or subcontractors, or subcontractors.

\section{Printed in the United States of America \\ United States Department of Energy \\ Office of Environmental Management Washington, DC}

This document is available on the U.S. DOE Information Bridge and on the CBP website: http://cementbarriers.org/ An electronic copy of this document is also available through links on the following websites: http://srnl.doe.gov/ and http://cementbarriers.org/ 


\section{FOREWORD}

The Cementitious Barriers Partnership (CBP) Project is a multi-disciplinary, multi-institutional collaboration supported by the United States Department of Energy (US DOE) Office of Tank Waste Management. The objective of the CBP project is to develop a set of tools to improve understanding and prediction of the longterm structural, hydraulic, and chemical performance of cementitious barriers used in nuclear applications.

A multi-disciplinary partnership of federal, academic, private sector, and international expertise has been formed to accomplish the project objective. In addition to the US DOE, the CBP partners are the Savannah River National Laboratory (SRNL), Vanderbilt University (VU), Energy Research Center of the Netherlands (ECN), and SIMCO Technologies, Inc. The Nuclear Regulatory Commission (NRC) is providing support under a Memorandum of Understanding. The National Institute of Standards and Technology (NIST) has provided research previously under an Interagency Agreement. Neither the NRC nor NIST are signatories to the CRADA.

The periods of cementitious performance being evaluated are up to and $>100$ years for operating facilities and $>1000$ years for waste management. The set of simulation tools and data developed under this project will be used to evaluate and predict the behavior of cementitious barriers used in near-surface engineered waste disposal systems, e.g., wasteforms, containment structures, entombments, and environmental remediation, including decontamination and decommissioning analysis of structural concrete components of nuclear facilities (spent-fuel pools, dry spent-fuel storage units, and recycling facilities such as fuel fabrication, separations processes). Simulation parameters will be obtained from prior literature and will be experimentally measured under this project, as necessary, to demonstrate application of the simulation tools for three prototype applications (wasteform in concrete vault, high-level waste tank grouting, and spent-fuel pool). Test methods and data needs to support use of the simulation tools for future applications will be defined.

The CBP project is a multi-year effort focused on reducing the uncertainties of current methodologies for assessing cementitious barrier performance and increasing the consistency and transparency of the assessment process. The results of this project will enable improved risk-informed, performance-based decision-making and support several of the strategic initiatives in the DOE Office of Environmental Management Engineering \& Technology Roadmap. Those strategic initiatives include 1) enhanced tank closure processes; 2) enhanced stabilization technologies; 3) advanced predictive capabilities; 4) enhanced remediation methods; 5) adapted technologies for site-specific and complex-wide D\&D applications; 6) improved SNF storage, stabilization and disposal preparation; 7) enhanced storage, monitoring and stabilization systems; and 8) enhanced long-term performance evaluation and monitoring. 


\section{EXECUTIVE SUMMARY}

This report presents the results of a study which intended to study the behavior of concrete samples placed in contact with a wasteform mixture bearing high level of sulfate in its pore solution. A setup was prepared which consisted in a wasteform poured on top of vault concrete mixes (identified as Vault 1/4 and Vault 2 mixes) cured for approximately 6 months. The main characteristics of the mixes are:

- Vault 1/4 concrete: water-to binder ratio (w/b) of 0.38 prepared with ASTM Type I/II cement and slag;

- Vault 2 concrete with a w/b ratio of 0.38 prepared with ASTM Type V cement, slag, fly ash, and silica fume.

The concrete mixtures were characterized in a separate study, as reported in CBP Report CBP-TR-2015-003, Rev. 0. The wasteform grout was prepared in laboratory according to the proportions of the saltstone mix designed by the Savanah River National Laboratory: 10\% cement, 45\% flay ash, 45\% slag.

The first portion of the study presented in this report focused on the characterization of transport properties of the cured saltstone mixture. Porosity and tortuosity were measured over a 2-year period, to assess the potential impact of hydration. Porosity measurements showed that the saltstone grout is very porous, with an average of $62.9 \%$. The test results also showed that porosity did not vary with time after 28 days of curing.

Tortuosity and diffusion coefficient values were measured on the basis of the migration test procedure, where species transport is accelerated using applied electrical potential. The measurements showed a decrease in electrical current values between 28 and 91 days, but was stable after that. The reduction in current values was attributed to hydration of cementitious materials. Analysis of the current curves revealed that despite its high porosity, the material exhibits very low tortuosity. The tortuosity value of the saltstone is lower than the tortuosity measured on Vault 1/4 and Vault 2 concrete mixtures. It is thus very resistant to species ingress or leaching.

In the second portion of the experimental program, a setup was prepared which consisted of saltstone poured on top of Vault concrete mixes cured for approximately 6 months. The system was sealed to maintain saturated conditions throughout the duration of the test. After 2 years, the materials were separated. Upon separation, no signs of chemical degradation were observed. This contrasted with another study (CBP Report CBP-TR-2015007, Rev. 1) where hydrated paste samples with the same cement, slag, fly ash and silica fume proportions as the Vault 2 mix were immersed in contact solutions with sulfate levels similar to those found in saltstone and showed alterations. One possible explanation for the absence of damage in the two-layer system is the slow exchange rate between the saltstone and concrete, owing to the low tortuosity of saltstone.

Concrete samples were analyzed to quantify the extent of species that diffused from saltstone. The concrete samples were milled over small depth increment. The collected powder samples were dissolved in acid before being analyzed to measure sodium, potassium, magnesium, calcium, nitrate/nitrite and sulfur content. Overall, only very concentrated species, such as sodium and nitrate/nitrite, showed clear signs of diffusing into concrete. Other species such as sulfate did not show significant ingress. 
Limited SEM/EDS observations were also performed on the Vault 2 concrete near the saltstone interface. Although ettringite could be observed in air bubbles near the concrete/saltstone interface, the concrete paste did not show signs of damage. A silica gel was also observed in some air bubbles. It was hypothesized that a silica-rich gel was the cause of severe degradation observed in hydrated pastes from the previous study on hydrated pastes. This siliceous phase observed in the present study may fit with this assumption, but more evidence is needed before this hypothesis can be confirmed. 



\section{CONTENTS}

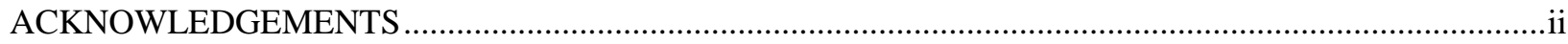



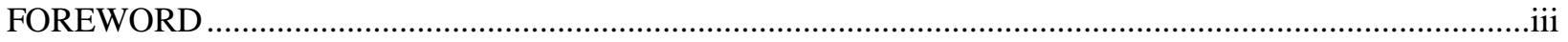

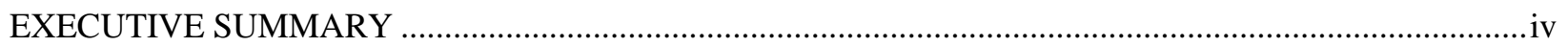



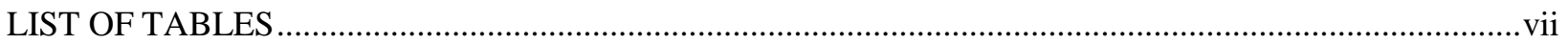

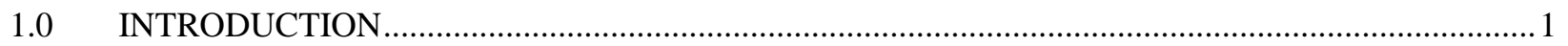

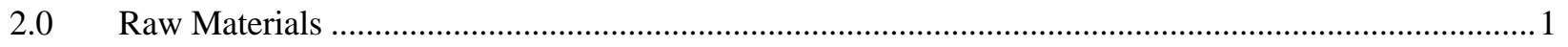

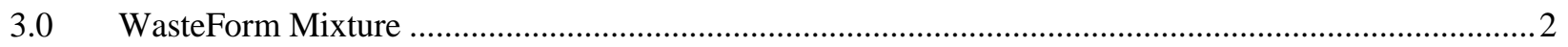



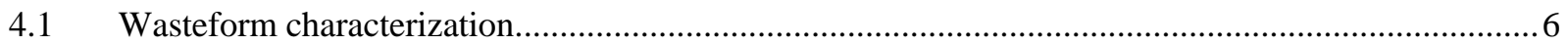





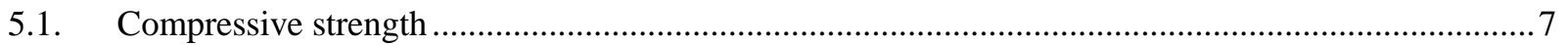

5.2. Chemical composition of expressed pore fluids.............................................................................



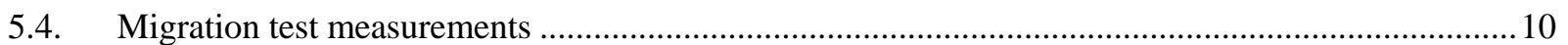

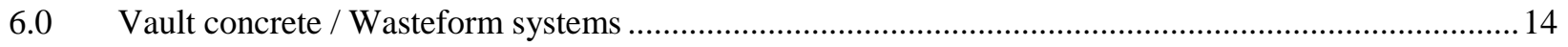

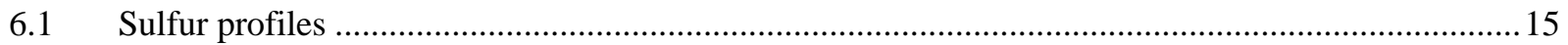

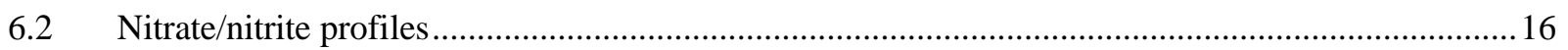

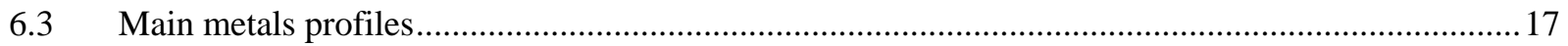

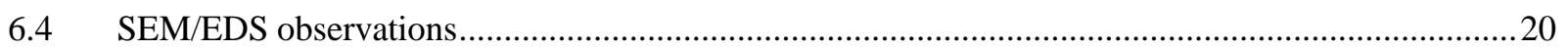

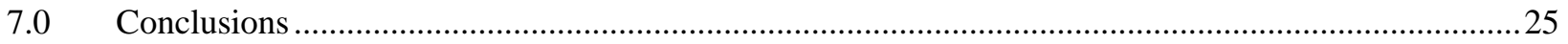

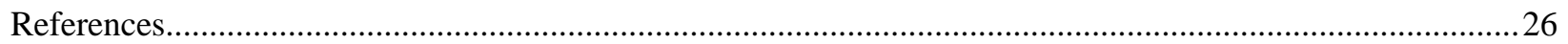

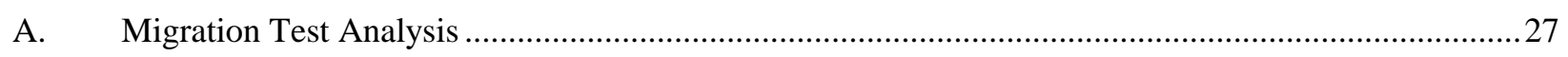




\section{LIST OF FIGURES}

Figure 1 - Plastic mold used to case Saltstone samples....................................................................................

Figure 2 - Wasteform / concrete 2-layer setup …….........................................................................................

Figure 3 - Wasteform mixture preparation......................................................................................................

Figure 4 - Experimental setup for pore solution extraction............................................................................ 8

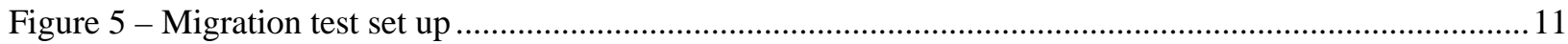

Figure 6 - Migration test current values after 28, 91 days and 1 and 2 years of curing .................................12

Figure 7 - Vault concrete / wasteform separation .............................................................................................. 14

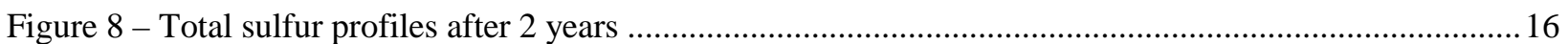

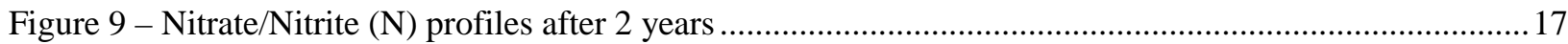

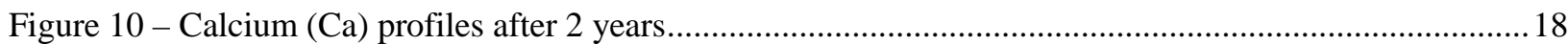

Figure 11 - Potassium (K) profiles after 2 years ……...................................................................................... 18

Figure 12 - Sodium (Na) profiles after 2 years ............................................................................................... 19

Figure 13 - Magnesium (Mg) profiles after 2 years ...................................................................................... 19

Figure 14 - SEM micrograph of Vault 2 concrete (x15) exposed to wasteform for 2 years .............................20

Figure 15 - SEM micrograph (x2000) and EDS analyses from Vault 2 concrete ............................................22

Figure 16 - SEM micrograph (x1500) and EDS analysis in a second air bubble ............................................23

Figure 17 - SEM micrograph (x1500) and EDS analyzes of unhydrated phases ..............................................24

Figure 18 - Simulation of migration test measurements 0.45 w/c OPC mixture, ..........................................29 


\section{LIST OF TABLES}

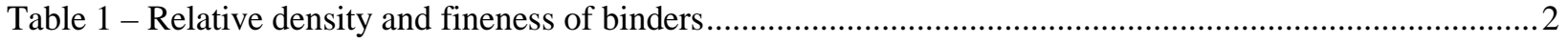

Table 2 - Chemical composition of binders (\%) .............................................................................................

Table 3 - Product content for wasteform mixing solution...................................................................................

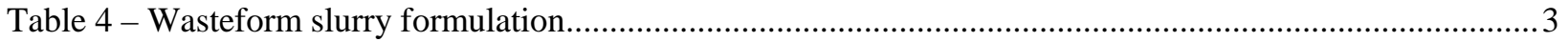

Table 5 - Wasteform compressive strength ................................................................................................... 7

Table 6 - Pore solution of Saltstone after 28 days of curing ............................................................................ 8

Table 7 - Porosity measurement after 28, 91 and 365 days of curing.............................................................10

Table 8 - Diffusion properties estimated from migration test analyses ..........................................................13

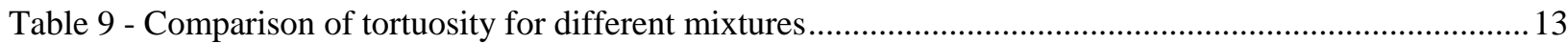

Table 10 - Element available (g/kg dried material) ..................................................................................... 15 



\subsection{INTRODUCTION}

Over the past years, several experiments were performed in the DOE-EM Cementitious Barriers Partnership program to provide data to support model development and help understand the potential degradation mechanisms of concrete exposed to a wasteform slurry known as saltstone.

Past experiments focused mostly on hydrated paste materials immersed in aggressive contact solutions (Protière and Samson, 2014a). The contact solutions were selected to isolate possible degradation mechanisms and specific conditions for which observations or data were needed. Analyses of samples after extended immersion periods were performed to measure the extent of degradation on these simplified systems.

In the present study, the objective was to get laboratory data from a system that is as close as possible to field conditions. A setup was prepared which consisted in saltstone poured on top of vault concrete mixes (identified as Vault 1/4 and Vault 2 mixes) cured for approximately 6 months. The main characteristics of the mixes are:

- Vault 1/4 concrete: water-to binder ratio (w/b) of 0.38 prepared with ASTM Type I/II cement and slag;

- Vault 2 concrete with a w/b ratio of 0.38 prepared with ASTM Type V cement, slag, fly ash, and silica fume.

The vault concrete mixtures were prepared in October 2011 and characterized over a two-year period. Results are presented in CBP-TR-2015-003, Rev. 0 (Protière and Samson, 2014b) and are not repeated in this document.

The two-layer system was sealed to maintain saturated conditions throughout the duration of the test. After two years, materials were separated and the concrete analyzed to quantify the extent of species that diffused from saltstone.

The details of the study are provided in the following sections.

\subsection{RAW MATERIALS}

This section presents the characteristics of the cements and supplementary cementing materials used in the preparation of wasteform and vault concretes materials. All materials were provided to SIMCO by Savannah River National Laboratory (SRNL) in September 2011. Relative densities and Blaine surfaces of binders are given in Table 1.

The chemical composition of binders is presented in Table 2. They were evaluated using the X-ray fluorescence technique. The table lists the main components. Trace elements, amounting for less than $2 \%$ of the total composition, are not listed. 
Table 1 - Relative density and fineness of binders

\begin{tabular}{|c|c|c|c|c|c|}
\hline & $\begin{array}{c}\text { Type I/II } \\
\text { cement } \\
\text { Lafarge }\end{array}$ & $\begin{array}{l}\text { Type V } \\
\text { cement } \\
\text { Lehigh }\end{array}$ & $\begin{array}{l}\text { GGBFS } \\
\text { Holcim }\end{array}$ & $\begin{array}{c}\text { Force } \\
10000 \text { SF } \\
\text { Grace }\end{array}$ & $\begin{array}{c}\text { Class F Fly } \\
\text { Ash } \\
\text { SEFA }\end{array}$ \\
\hline $\begin{array}{l}\text { Relative density } \\
\left(\mathrm{g} / \mathrm{cm}^{3}\right)\end{array}$ & 3.182 & 3.224 & 2.924 & 2.259 & 2.432 \\
\hline $\begin{array}{l}\text { Blaine surface } \\
\left(\mathrm{cm}^{2} / \mathrm{g}\right)\end{array}$ & 4340 & 3765 & 5990 & 2055 & 4055 \\
\hline
\end{tabular}

Table 2 - Chemical composition of binders (\%)

\begin{tabular}{lccccc}
\hline Oxides & $\begin{array}{c}\text { Type I/II } \\
\text { cement } \\
\text { Lafarge }\end{array}$ & $\begin{array}{c}\text { Type V } \\
\text { cement } \\
\text { Lehigh }\end{array}$ & GGBFS & $\begin{array}{c}\text { Force } \\
\mathbf{1 0 0 0 0} \text { SF } \\
\text { Grace }\end{array}$ & $\begin{array}{c}\text { Class F Fly } \\
\text { Ash } \\
\text { SEFA }\end{array}$ \\
\hline $\mathrm{CaO}$ & 64.8 & 63.8 & 37.8 & 0.60 & 1.32 \\
$\mathrm{SiO}_{2}$ & 20.9 & 21.0 & 39.6 & 95.0 & 54.5 \\
$\mathrm{Al}_{2} \mathrm{O}_{3}$ & 4.80 & 3.82 & 7.61 & 0.18 & 28.1 \\
$\mathrm{Fe}_{2} \mathrm{O}_{3}$ & 3.43 & 4.75 & 0.47 & 0.07 & 8.65 \\
$\mathrm{SO}_{3}$ & 1.75 & 1.15 & 1.05 & 0.18 & $<0.1$ \\
$\mathrm{MgO}$ & 1.05 & 2.60 & 12.2 & 0.22 & 1.19 \\
$\mathrm{~K}_{2} \mathrm{O}$ & 0.54 & 0.61 & 0.47 & 0.48 & 2.82 \\
$\mathrm{Na}_{2} \mathrm{O}$ & 0.22 & 0.15 & 0.28 & 0.18 & 0.41 \\
$\mathrm{LOI}$ & 1.13 & 0.84 & -0.45 & 3.32 & 1.41 \\
\hline
\end{tabular}

Type I Portland cement is known as common or general purpose cement. Type V cement is commonly used in sulfate-rich aggressive environments. It has very low aluminate (C3A) content and is thus less prone to formation of expansive mineral phases upon sulfate ingress.

\subsection{WASTEFORM MIXTURE}

This section details the wasteform preparation. The wasteform mixture was prepared in March 2012. The mix design was provided by SRNL. To be consistent with the identification used in CBP-TR-2015-003, Rev. 0 (Protière and Samson, 2014b), the saltstone prepared for this test series is identified as saltstone or WS-2 for the remainder of the report ${ }^{1}$. The salt solution used to batch the material was prepared following the composition presented in Table 3. The relative density of the solution, measured at $23^{\circ} \mathrm{C}$, was $1.223 \mathrm{~g} / \mathrm{cm}^{3}$.

${ }^{1}$ In reference CBP-TR-2015-003, Rev. 0 (Protière and Samson, 2014b), two different wasteform mixes were prepared and tested. They were labeled WS-1 and WS-2. In the present report, the material was prepared according to the WS-2 proportions. 
Table 4 gives the wasteform formulation prepared for this project. It was designed by SRNL as a 10\%, $45 \%$ and $45 \%$ mixture of cement, slag and fly ash.

Table 3 - Product content for wasteform mixing solution

\begin{tabular}{ccccc}
\hline & \multicolumn{4}{c}{ Mixing solution composition } \\
Chemicals & M.M. & $\begin{array}{c}\text { Molality } \\
\text { (mmol/L } \\
\text { of DI water) }\end{array}$ & $\begin{array}{c}\text { (g/L } \\
\text { of DI water) }\end{array}$ & $\begin{array}{c}\text { Molarity } \\
\text { (mmol/L } \\
\text { of solution) }\end{array}$ \\
\hline $\mathrm{NaOH}$ & 40.00 & 1590 & 63.6 & 1381 \\
$\mathrm{NaNO}_{3}$ & 84.99 & 3160 & 268.6 & 2744 \\
$\mathrm{NaNO}_{2}$ & 69.00 & 370 & 25.5 & 321 \\
$\mathrm{Na}_{2} \mathrm{CO}_{3}$ & 105.99 & 180 & 19.1 & 156 \\
$\mathrm{Na}_{2} \mathrm{SO}_{4}$ & 142.04 & 60 & 8.5 & 52 \\
$\mathrm{Al}_{3}\left(\mathrm{NO}_{3}\right)_{3} \cdot\left(9 \mathrm{H}_{2} \mathrm{O}\right)$ & 429.10 & 50 & 21.5 & 43 \\
$\mathrm{Na}_{3} \mathrm{PO}_{4} \cdot\left(12 \mathrm{H}_{2} \mathrm{O}\right)$ & 380.13 & 10 & 3.8 & 9 \\
\hline $\mathrm{TOTAL}$ & & & 410.6 & \\
\hline
\end{tabular}

Table 4 - Wasteform slurry formulation

\begin{tabular}{lc}
\hline Raw materials & $\begin{array}{c}\text { Wasteform WS-2 } \\
\left(\mathbf{k g} / \mathbf{m}^{3}\right)\end{array}$ \\
\hline Type I/II Cement (Lafarge) & 94 \\
GGBFS (Holcim) & 423 \\
Class F Fly Ash (SEFA) & 423 \\
Salt Solution & 796 \\
\hline \multicolumn{1}{c}{ DI Water } & 564 \\
\multicolumn{1}{c}{ Salt } & 232 \\
\hline Theoretical mix density & 1703 \\
\hline Water/binder ratio, w/b & 0.60 \\
\hline
\end{tabular}

A special procedure for mixing and casting samples of the wasteform slurry was followed based on ASTM C938 - 02 Standard Practice for proportioning grout mixture for preplaced-aggregate concrete. Two batches of $10 \mathrm{~L}$ were prepared as follow:

- The three solid binders were weighted and transferred into a five-gallon plastic bucket to be premixed.

- The mixing solution described in Table 3 was poured in less than one minute while stirring using a helicoid impeller. 
- $\quad$ The mixing of the slurry lasted five minutes, using a helicoid impeller, (Figure 3a).

- The wasteform mix was then poured into plastic cylindrical molds of $80 \mathrm{~mm}$ in height and $100 \mathrm{~mm}$ in diameter, (Figure 3b). Details of plastic cylindrical molds are illustrated in Figure 1. A plastic film was place on each cylindrical mold in order to keep the material under sealed conditions after casting. The samples prepared in molds were used for characterization.

- Some of the mix was also poured on existing Vault 1/4 and Vault 2 mixes prepared in October 2011. Concrete cylinders were first cut in half. With the sawn concrete surfaces placed upward, an 80-mm high and 100-mm diameter plastic mold was fitted to the concrete as illustrated in Figure 2. The wasteform was poured into the mold. After pouring, the whole external concrete surface was sealed with wax. The final concrete/wasteform system is presented in Figure 2. The concrete had been cured for approximately 180 days when it was placed in contact with saltstone.

- Finally, $50 \mathrm{~mm}$ cube specimens were cast from each batch according to the procedure described in ASTM C305 - Mechanical Mixing of Hydraulic Cement Pastes and Mortars of Plastic Consistency.

The steps of wasteform preparation are illustrated in Figure 3. Density of the fresh wasteform slurry was measured at $1695 \mathrm{~kg} / \mathrm{m}^{3}$, which is in accordance to the theoretical mixture density presented in Table 4 .

For the initial curing phase, the samples were kept in molds in the laboratory. A plastic membrane was used on top of each mold to maintain wet conditions. After 3 days, cylinders were carefully removed from their molds (Figure 1), and cured in the salt solution described in Table 3.

Concrete-wasteform 2-layer systems were not demolded until analyzed. Salt solution was placed on top of the Saltstone layer to maintain saturated conditions. The solution was renewed monthly. The top of the mold was sealed with a plastic membrane.

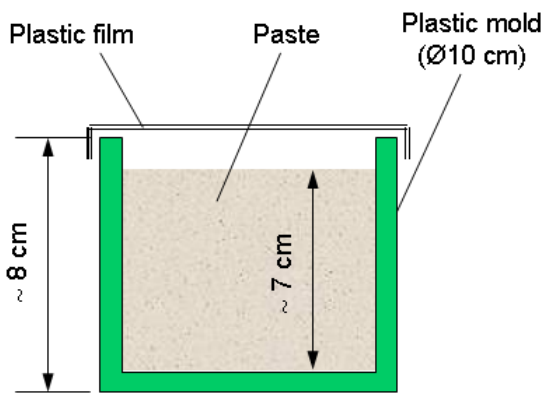

Figure 1 - Plastic mold used to case Saltstone samples 


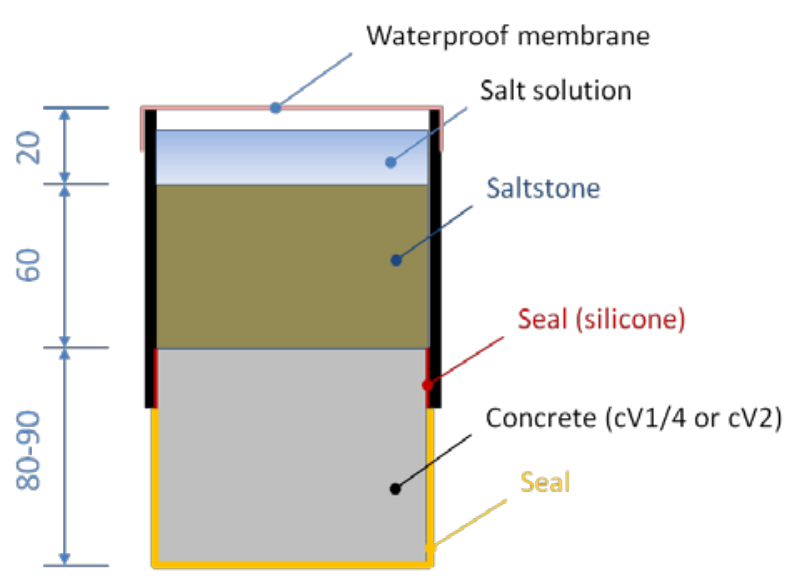

Dimensions in millimeters

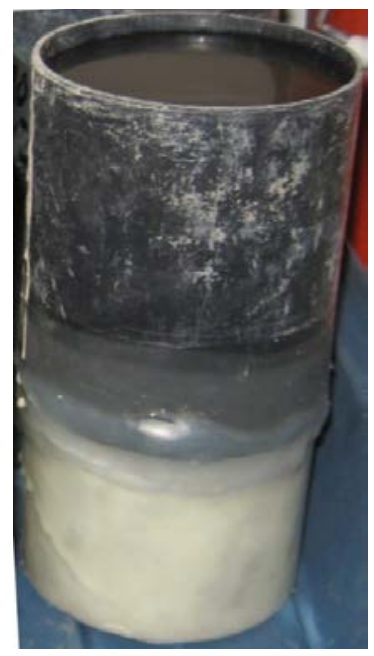

Figure 2 - Wasteform / concrete 2-layer setup

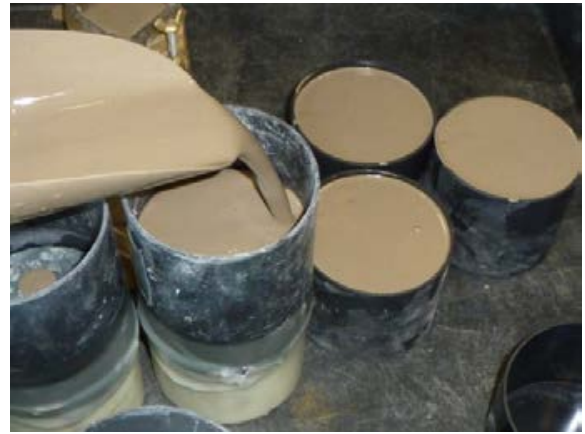

b) Sampling

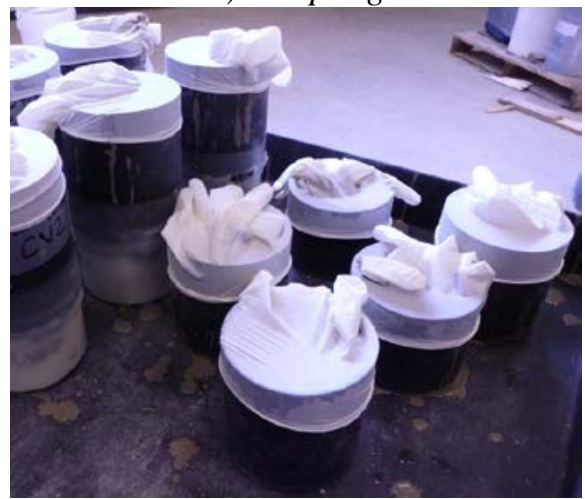

c) Curing 3 days

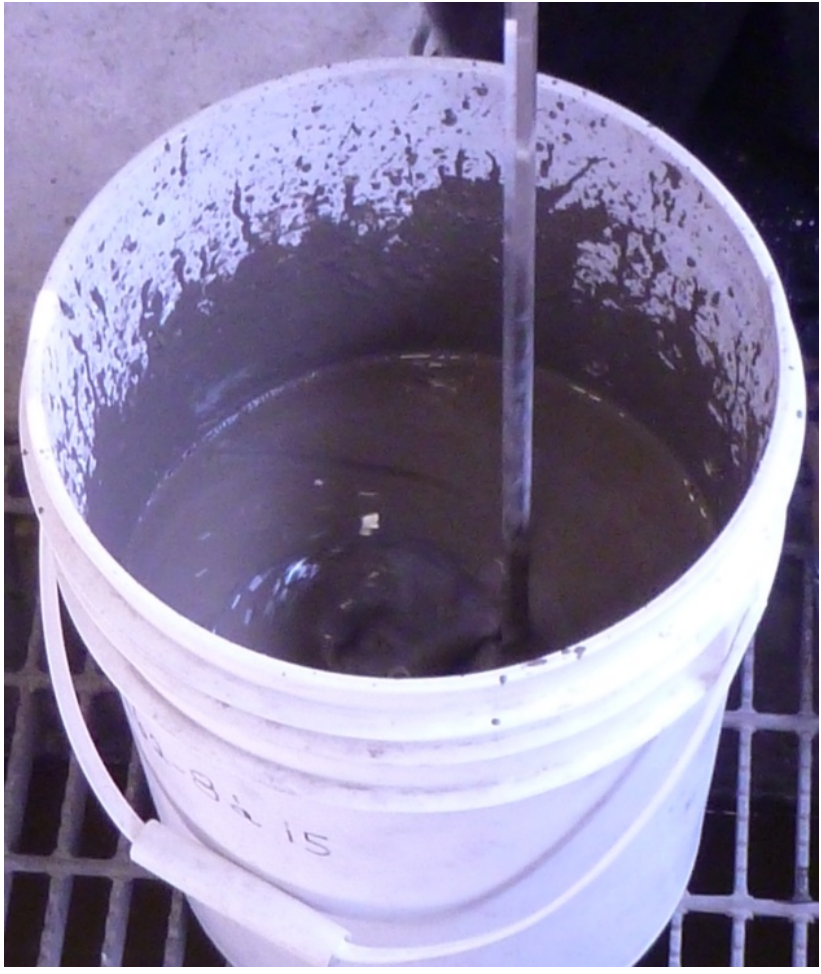

a) Mixing

Figure 3 - Wasteform mixture preparation 


\subsection{EXPERIMENTAL PROGRAM}

The main objectives of the study were to measure the transport properties of the wasteform material and, to measure the extent of chemical species diffusion from Saltstone to concrete in the 2-layer system. The experimental program is detailed in the present section.

\subsection{Wasteform characterization}

Tests were performed after different curing period to characterize materials. The following tests were performed:

- Compressive strength measurements have been performed at 28 days on 50-mm cube specimens;

- Pore solution extraction of solution by applied mechanical pressure was performed after 28 days of curing.

- Porosity ${ }^{2}$ : based on a modified version of ASTM Standard C642 - Standard Test Method for Density, Absorption, and Voids in Hardened Concrete procedure. Measurements were performed after 28, 91 and 365 days of curing.

- Diffusion coefficients: measured on the basis of migration tests, a modified version of the ASTM C1202 procedure: Standard Test Method for Electrical Indication of material's Ability to Resist Chloride Ion Penetration. The procedure was performed after 28 and 91 days, 1 year and 2 years of curing.

\subsection{Vault concrete / Wasteform system}

After two years of contact, Saltstone and concrete samples were separated. The following tests were then performed:

- Sulfur content profiles by combustion and infrared dosage, in accordance with MA. 310 - CS 1.0 procedure.

- Nitrates content profiles by ion chromatography, in accordance with MA. 300 - Ions 1.3 procedure.

- Main alkalis (calcium, sodium, potassium, magnesium) content profiles by Microwave PlasmaAtomic Emission Spectroscopy.

- Scanning Electron Microscopy (SEM) and Energy-dispersive X-ray spectroscopy (EDS) examinations on Vault 2 concrete.

\footnotetext{
${ }^{2}$ The use of porosity in the report refers to the volume fraction of permeable voids, as measured with the ASTM C642 procedure.
} 


\subsection{SALTSTONE CHARACTERIZATION RESULTS}

\subsection{Compressive strength}

Compressive strength was tested based on ASTM C109 Standard Test Method for Compressive Strength of Hydraulic Cement Mortars, using 50-mm cube specimens. Three samples were tested for compressive strength at 28 days. Results are presented in Table 5. Average compressive strength of the wasteform material at 28 days is $5.9 \mathrm{MPa}$.

Table 5 - Wasteform compressive strength

\begin{tabular}{lcccc}
\hline & WS-2 \#1 & WS-2 \#2 & WS-2 \#3 & Average \\
\hline $\begin{array}{l}\text { Compressive strength } \\
\text { (MPa) }\end{array}$ & 5.1 & 6.0 & 6.7 & $\mathbf{5 . 9}$ \\
\hline
\end{tabular}

\subsection{Chemical composition of expressed pore fluids}

The pore solution extraction procedure consists of applying sufficient pressure on a paste sample to extract the solution from the material. Pore solution was extracted by squeezing crushed samples under compressive loading using the device shown in Figure 4. Solution was delivered through a drain ring and channel and recovered with a syringe in order to limit the exposure to the atmosphere. Pore solution analyses were carried out shortly after the extraction tests.

Solution extraction was performed after 28 days of curing in salt solution. The specimens for pore solution extraction were sawn from cylinders. Samples were broken in small pieces, placed in the cell, and crushed at a high pressure. Pore solution analyses were carried out using an Atomic Absorption Analyzer and Ion Chromatography as well as $\mathrm{pH}$ titration to obtain the contents of the main species in the pore solution. Table 6 presents the results of the chemical composition of the extracted solution.

The second column in Table 6 gives the concentration as measured. The electrical charge balance for the asmeasured results is not strictly neutral, which is a result of experimental errors associated with measuring the concentrations of the ions. The corrected values are presented in the last column. The correction applied to species is proportional to their respective weight in the solution.

The concentration of $\mathrm{Na}^{+}, \mathrm{K}^{+}, \mathrm{NO}_{2}{ }^{-}$and $\mathrm{NO}_{3}{ }^{-}$is close to their respective concentrations in the batch solution presented in Table 3. This indicates weak adsorption and substitution levels in the solid matrix. 


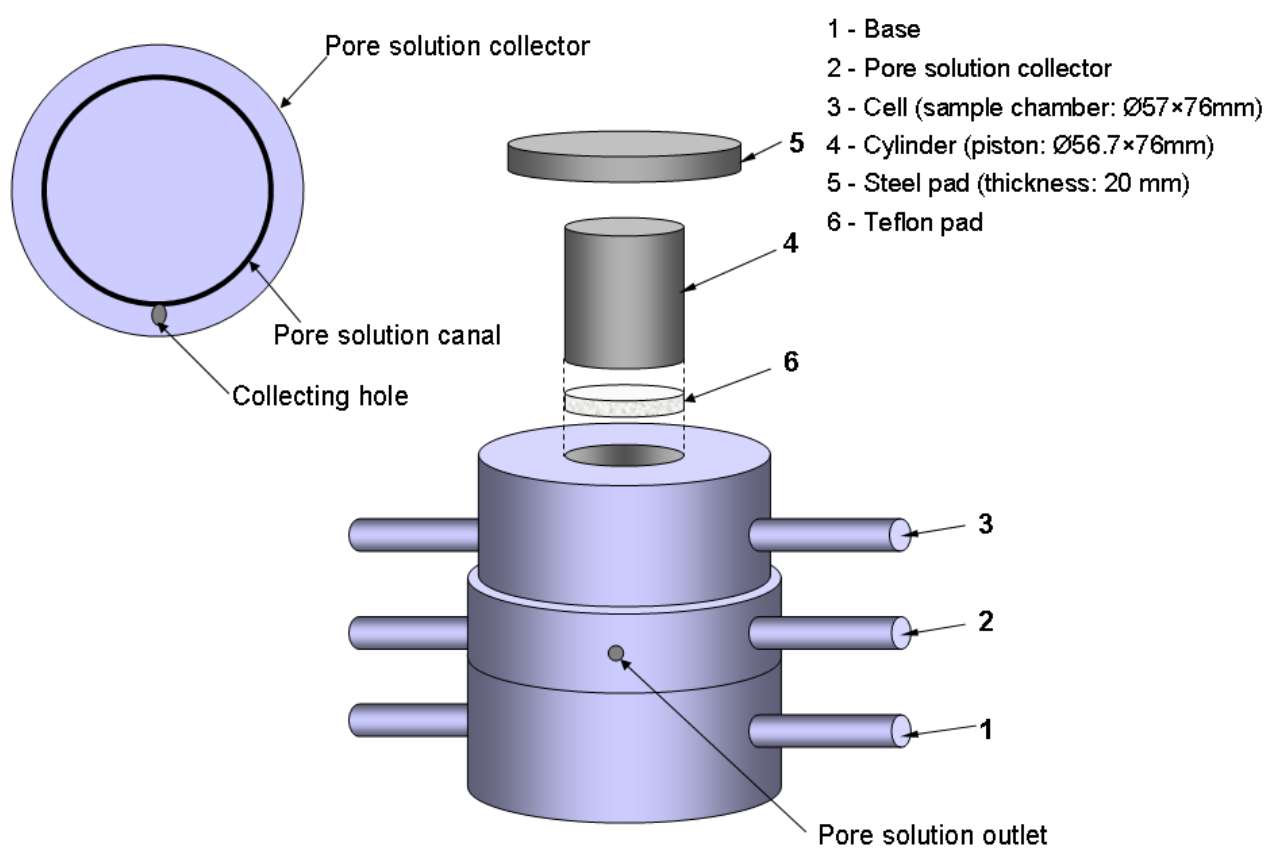

Figure 4 - Experimental setup for pore solution extraction

Table 6 - Pore solution of Saltstone after 28 days of curing

\begin{tabular}{|l|c|c|}
\hline Species & $\begin{array}{c}\text { Extracted solution } \\
\text { as measured } \\
\text { (mmol/L) }\end{array}$ & $\begin{array}{c}\text { Solution adjusted for } \\
\text { electroneutrality } \\
\text { (mmol/L) }\end{array}$ \\
\hline $\mathrm{SO}_{4}{ }^{2-}$ & 123.9 & 123.6 \\
\hline $\mathrm{NO}_{3}{ }^{-}$ & 3348.4 & 3339.3 \\
\hline $\mathrm{NO}_{2}{ }^{-}$ & 364.8 & 363.8 \\
\hline $\mathrm{CO}_{3}{ }^{2-}$ & 52.5 & 52.4 \\
\hline $\mathrm{OH}^{-}$ & 430.4 & 429.2 \\
\hline $\mathrm{Cl}^{-}$ & 22.3 & 22.2 \\
\hline $\mathrm{Na}^{+}$ & 4249.7 & 4261.3 \\
\hline $\mathrm{K}^{+}$ & 244.5 & 245.2 \\
\hline $\mathrm{Ca}^{2+}$ & $<0.1$ & 0.1 \\
\hline
\end{tabular}




\subsection{Porosity measurements}

Porosity measurements were performed in accordance with ASTM C642 standard procedure: Standard Test Method for Density, Absorption and Voids in Hardened Concrete for the vault mixes presented in report CBPTR-2015-003, Rev. 0. However, the procedure had to be modified (discussed below) to account for the specific nature of saltstone. Trial tests showed that samples sawn from cured cylinders lost weight when they were submerged in water or placed in a fog room due to salt leaching. It is impossible to soak samples to improve their saturation without changing the ion composition of the pore solution. Given the highly-charged pore solution, this leaching affects the overall mass of the samples. Also, the drying at $110{ }^{\circ} \mathrm{C}$, which is integral to the ASTM C642 procedure, severely damaged the wasteform samples, most probably the result of salt crystallization.

Compared to the ASTM procedure, the procedure used here was reversed: drying of samples was performed at the end of the procedure instead of the beginning. Samples were placed in a plate to avoid losing pieces when it broke due to crystallization pressure. Also, the boiling sequence at the end of the procedure was eliminated. This step is usually performed to ensure that samples are fully saturated. Here, it was assumed that samples were fully saturated initially, since they were cured in salt solution. The initial mass was thus assumed to be the same as the saturated mass. Finally, the calculations accounted for the density of the pore solution, which is not equivalent to the density of water.

The mass of the pore solution $M_{\text {sol }}$ is given by $M_{\text {sol }}=M_{H 20}+M_{\text {salts }}$, where $M_{H 20}$ and $M_{\text {salts }}$ are the mass of water and the mass of salts dissolved in the pore solution. The mass of water $M_{\mathrm{H} 20}$ is deduced from the mass after drying at $110^{\circ} \mathrm{C}$ :

$$
M_{H 2 O}=M_{i n i t}-M_{d r y}
$$

The pore solution volume $\left[\mathrm{cm}^{3}\right]$ is then given by:

$$
V_{\text {sol }}=\frac{M_{\mathrm{H}_{2} \mathrm{O}}+M_{\text {salts }}}{d_{\text {sol }}}
$$

where $d_{\text {sol }}$, the density of the pore solution. The mass of salts depends on the ion concentrations and on the pore solution volume: $M_{\text {salts }}=c_{\text {salts. }} V_{\text {sol }}$, where $c_{\text {salts }}$ is the mass of all the salts dissolved in the pore solution per unit volume. The volume of pore solution, i.e. the pore volume, is then given by:

$$
V_{\text {sol }}=\frac{M_{\mathrm{H}_{2} \mathrm{O}}}{d_{\text {sol }}-c_{\text {salts }}}
$$

As the pore solution is mainly composed of sodium nitrate, it is assumed to be equivalent to a $\mathrm{NaNO}_{3}$ solution. According to the pore solution compositions given in Table 6, the $\mathrm{NaNO}_{3}$ concentration of this approximated pore solution is set to $4.0 \mathrm{~mol} / \mathrm{L}$. The relative density $d_{\text {sol }}$ for a $4.0 \mathrm{~mol} / \mathrm{L} \mathrm{NaNO}_{3}$ solution is $1.17^{3}$, which is in

${ }^{3}$ Handbook of Chemistry and Physics, CRC Press, 1985/86. 
agreement with the relative density measured on the batching solution. The concentration $c_{\text {salts }}$ of this $4.0 \mathrm{~mol} / \mathrm{L} \mathrm{NaNO}_{3}$ solution is equal to $0.34 \mathrm{~g} / \mathrm{cm}^{3}$.

The sample volume $V_{s}$ is deduced by measuring the initial sample mass $M_{\text {init }}$ and its mass measured under water $M_{\text {init }}^{\text {imm }}$, using the following expression:

$$
V_{s}=\frac{M_{\text {init }}-M_{\text {init }}^{\text {imm }}}{d_{H_{2} \mathrm{O}}}
$$

where $d_{\mathrm{H}_{2} \mathrm{O}}$, the density of water $\left[\mathrm{g} / \mathrm{cm}^{3}\right]$. The porosity value is then calculated using the following expression:

$$
\phi=\frac{V_{\text {sol }}}{V_{s}}
$$

Table 7 details the measurement of the porosity tests after 28 days, 91 days and 1 year of curing. The average value of porosity is $62.9 \%$. The values are very high, which can be expected for paste materials prepared without sand or aggregates. Values can be compared to experimental data published in (Taylor 1997, figure 85) and compared to Powers' porosity model. In this reference, porosity values for ordinary Portland cement pastes prepared at a w/c ratio of 0.65 are around $50 \%$. Present results show that the porosity of the wasteform remains almost constant from 28 to 365 days of hydration.

Table 7 - Porosity measurements after 28, 91 and 365 days of curing

\begin{tabular}{ll|cc|cc|cc}
\hline Designation & Units & \multicolumn{2}{c|}{ 28 days } & \multicolumn{2}{c|}{ 91 days } & \multicolumn{2}{c}{1 year } \\
& & $\# \mathbf{1}$ & \#2 & $\# \mathbf{1}$ & \#2 & \# 1 & \#2 \\
\hline$M_{\text {init }}$ & $(\mathrm{g})$ & 214.53 & 211.61 & 434.48 & 410.47 & 341.48 & 367.06 \\
$M_{\text {init }}^{\text {imm }}$ & $(\mathrm{g})$ & 90.19 & 89.00 & 183.32 & 173.15 & 143.36 & 154.29 \\
$M_{d r y}$ & $(\mathrm{~g})$ & 149.41 & 147.23 & 305.05 & 287.73 & 236.17 & 255.16 \\
$M_{H 2 O}$ & $(\mathrm{~g})$ & 65.12 & 64.38 & 129.43 & 122.74 & 105.31 & 111.90 \\
$\mathrm{~V}_{\text {tot }}$ & $\left(\mathrm{cm}^{3}\right)$ & 124.59 & 122.85 & 251.66 & 237.79 & 198.51 & 213.19 \\
Dry density & $\left(\mathrm{g} / \mathrm{cm}^{3}\right)$ & 1.20 & 1.20 & 1.21 & 1.21 & 1.19 & 1.20 \\
Porosity & $(\% \mathrm{vol})$ & 63.0 & 63.1 & 62.0 & 62.2 & 63.9 & 63.2 \\
\hline
\end{tabular}

\subsection{Migration test measurements}

The objective of the migration test is to determine the tortuosity and diffusion coefficients of Waste Form mixture. The test is a modified version of the ASTM C1202 procedure - Standard Test Method for Electrical Indication of Concrete's Ability to Resist Chloride Ion Penetration. The method is part of the Unified Facilities Guide Specification (UFGS-03 31 29, 2010) durability guidelines issued by the US Navy. The method, 
developed by SIMCO, consists in accelerating the ions under an external potential and measuring the electrical current passing through the test specimen over a 10 to 15-day period. The setup is illustrated on Figure 5.

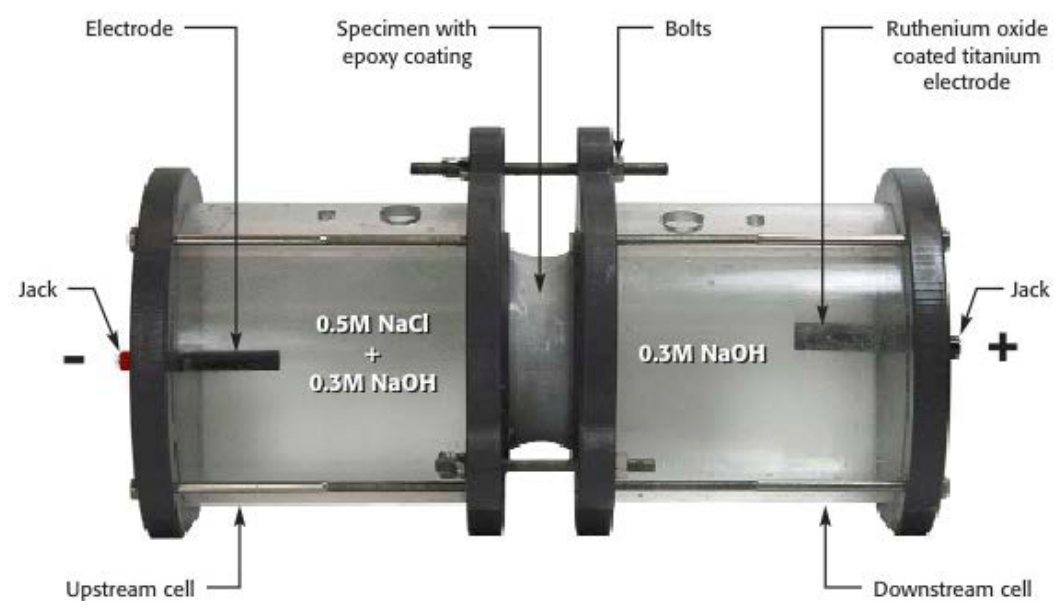

Figure 5 - Migration test set up

The test was performed on samples $100 \mathrm{~mm}$ in diameter and from 25 to $30 \mathrm{~mm}$ in thickness. For each test condition, two disks were tested. Discs were mounted between cells filled with $2.7 \mathrm{~L}$ of $0.3 \mathrm{M} \mathrm{NaOH}$ solution. The upstream cell solution also contained $0.5 \mathrm{M}$ dissolved $\mathrm{NaCl}$ salt. Testing after 28 days of curing was performed at $15 \mathrm{~V}$. However, the combination of high voltage and high concentration in the pore solution proved difficult to analyze, due to the strong nonlinear coupling between species. For the tests after 91 days, 1 year and 2 years of curing, voltage was lowered to $6 \mathrm{~V}$. Voltage was measured regularly to make sure it was constant over the testing duration.

The measured currents $I_{a}$ are presented on Figure 6 for each curing period. The average of current values on two disks is plotted in solid line, and values for individual samples in dotted line. In order to be able to compare current values from one test condition to another, currents for 28-day samples were normalized to $6 \mathrm{~V}$ values. Results are particularly low, indicating a very good resistance to species transport.

As indicated by the current curves, the wasteform diffusion coefficients tend to decrease after 28 days of moist curing. However, after 91 days, there is no clear trend in the measured currents, which indicates stabilization of the diffusion properties. 


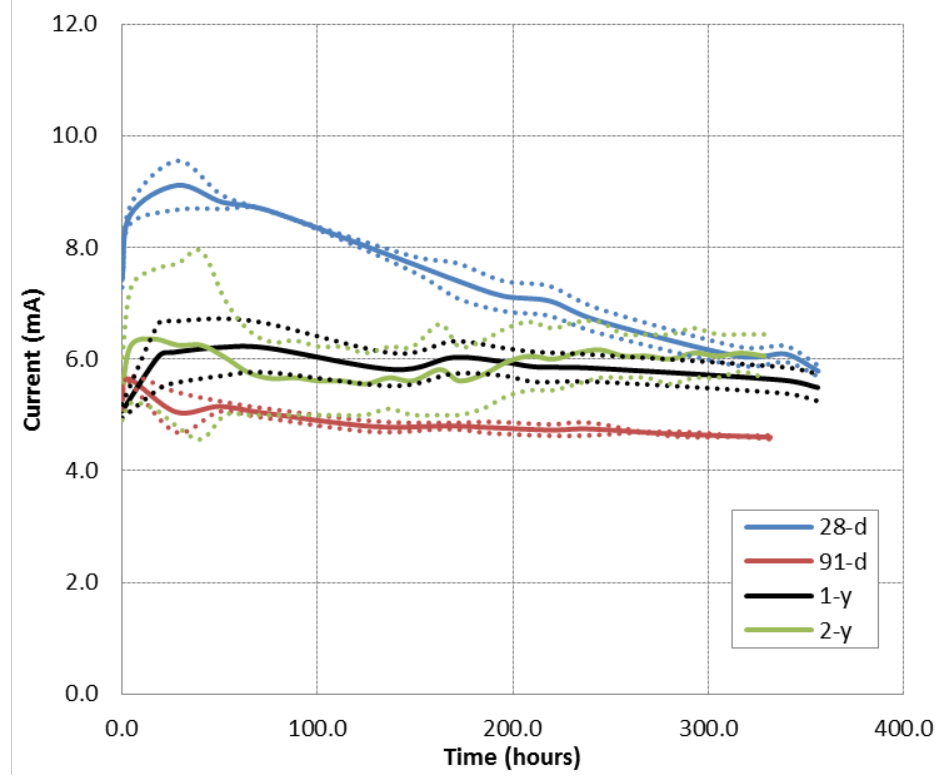

Figure 6 - Migration test current values after 28, 91 days and 1 and 2 years of curing

After the testing period, the measured currents were analyzed with the STADIUM ${ }^{\circledR}$-IDC laboratory module to evaluate the diffusion coefficients. The module iteratively tries to find the set of diffusion coefficients that reproduces the measured current curves. The analysis uses the porosity, pore solution concentrations and mixture composition parameters as input data. Details on the analysis are provided in (Samson 2008) and Appendix A. The analysis provides the tortuosity of the mixture, as well as the diffusion coefficients of chemical species, expressed as:

$$
D_{i}=\tau_{s} D_{i}^{o}
$$

where $D_{i}$ is the diffusion coefficient of species $i, \tau_{s}$ is the intrinsic tortuosity of the material and $D_{i}^{o}$ is the selfdiffusion coefficient of species $i$, which can be found in electrochemistry textbooks.

For normal cementitious materials, chloride reacts with monosulfate to form Friedel salt. This reaction is impeded at high $\mathrm{pH}$. For the analysis of Saltstone migration test results, it was assumed that no chemical interaction between chloride in the upstream cell and the hydrated phases of the mixture, owing to the presence of $\mathrm{NaOH}$ in both cells of the setup and the high $\mathrm{pH}$ of the saltstone pore solution.

The diffusion coefficients and tortuosities are presented in Table 8. The diffusion coefficients are presented for hydroxide and sulfate. As mentioned previously, the analyses for 28-day measurements could not be performed due to a problem with the numerical algorithm. The slight increase of tortuosity values with time is most probably a result of measurement variability and not a characteristic of the material itself. For all intents and purposes, the tortuosity of saltstone can be considered constant once 91 days of curing has been reached. Comparison with tortuosities of the Vault 2 and Vault 1/4 mixes are presented in Table 9. This clearly highlights the very small diffusive properties of the wasteform mix. 
Table 8 - Diffusion properties estimated from migration test analyses

\begin{tabular}{|c|c|c|c|c|}
\hline \multirow[b]{2}{*}{ Age of material } & \multirow[b]{2}{*}{ Sample ID. } & \multicolumn{3}{|c|}{ Wasteform } \\
\hline & & $\begin{array}{c}D_{\mathrm{OH}} \\
{\left[\mathrm{E}-11 \mathrm{~m}^{2} / \mathrm{s}\right]}\end{array}$ & $\begin{array}{c}D_{\mathrm{SO} 4} \\
{\left[\mathrm{E}-11 \mathrm{~m}^{2} / \mathrm{s}\right]}\end{array}$ & $\begin{array}{c}\text { Tortuosity } \\
\text { [E-5] }\end{array}$ \\
\hline \multirow{2}{*}{28 days } & 1 & $\mathrm{n} / \mathrm{a}$ & $\mathrm{n} / \mathrm{a}$ & $\mathrm{n} / \mathrm{a}$ \\
\hline & 2 & $\mathrm{n} / \mathrm{a}$ & n/a & $\mathrm{n} / \mathrm{a}$ \\
\hline \multirow{2}{*}{91 days } & 1 & 0.040 & 0.008 & 7.59 \\
\hline & 2 & 0.050 & 0.010 & 9.48 \\
\hline \multirow{2}{*}{1 year } & 1 & 0.050 & 0.010 & 9.48 \\
\hline & 2 & 0.050 & 0.010 & 9.48 \\
\hline \multirow[t]{2}{*}{2 years } & 1 & 0.060 & 0.012 & 11.4 \\
\hline & 2 & 0.060 & 0.012 & 11.4 \\
\hline \multicolumn{2}{|l|}{ Average } & 0.052 & 0.010 & 9.81 \\
\hline
\end{tabular}

Table 9 - Comparison of tortuosity for different mixtures

\begin{tabular}{cccc}
\hline \multirow{2}{*}{ Age of material } & Wasteform & $\begin{array}{c}\text { Tortuosity (E-5) } \\
\text { Vault 1/4 }\end{array}$ & Vault 2 \\
\hline 91 days & 8.54 & 860 & 300 \\
1 year & 9.48 & 700 & 380 \\
2 years & 11.4 & 610 & 50 \\
\hline
\end{tabular}




\subsection{VAULT CONCRETE / WASTEFORM SYSTEMS}

After two years, the saltstone/concrete 2-layer systems were cleaned of the wax layer and separated using a metal saw blade. The objective of the tests is to measure the extent of species contamination in the concrete layer, as illustrated on Figure 7.
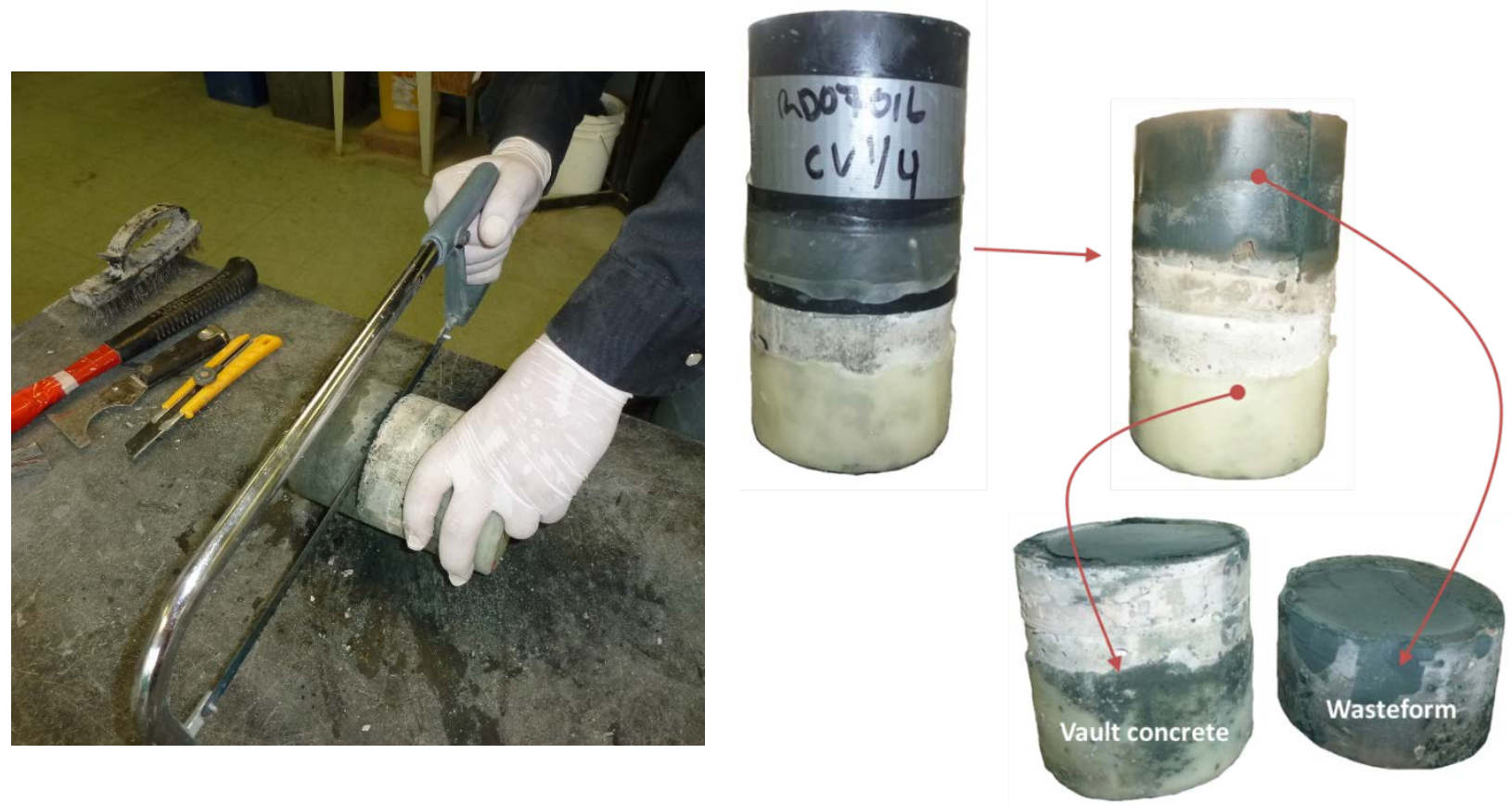

Figure 7 - Vault concrete / wasteform separation

Successive layers were milled with a grinding bit from the surface of the concrete sample corresponding to the exposed surface. The nominal thickness of each layer is $2 \mathrm{~mm}$, and grinding was performed over $30 \mathrm{~mm}$. A few layers were also milled in the wasteform, to provide comparison with results in concrete.

The powder collected over each depth was dissolved in acid to get an analytical solution, in accordance with the ASTM 1152 - Standard Test Method for Acid-Soluble Chloride in Mortar and Concrete test method. Different analytical methods were used, depending on the species of interest:

- Sulfur content profiles by combustion and infrared dosage, MA. 310 - CS 1.0.

- $\quad$ Nitrates content profiles by ion chromatography, MA. 300 - Ions 1.3.

- Main metals (calcium, sodium, potassium, magnesium) contents profiles by Microwave PlasmaAtomic Emission Spectroscopy.

- Scanning Electron Microscopy (SEM) and Energy-dispersive X-ray spectroscopy (EDS) examinations on Vault 2 concrete. 
Main observations from these measurements are presented in the following sections. On each figure presenting profiles of a specific chemical element, baselines are also plotted. These baselines correspond to the theoretical initial content of the element in the material. Those values are calculated from the binder's chemical composition (Table 2) and concrete mixture composition, as presented in report CBP-TR-2015-003, Rev. 0. For instance, in the case of calcium in the wasteform, the calculation is the weighted sum of $\mathrm{Ca}$ (from $\mathrm{CaO}$ ) in cement, slag and fly ash. The calculation accounts for both hydrated and unhydrated fractions of elements, which makes comparison with measurements easier, as chemical analysis following acid dissolution captures both. The complete calculation for calcium is illustrated here ${ }^{4}$ :

$$
\begin{gathered}
94 \frac{\mathrm{kg} \mathrm{cem}}{\mathrm{m} 3 \mathrm{salt}} \times 648 \frac{\mathrm{g} \mathrm{CaO}}{\mathrm{kg} \mathrm{cem}}+423 \frac{\mathrm{kg} \mathrm{GGBFS}}{\mathrm{m} 3 \mathrm{salt}} \times 378 \frac{\mathrm{g} \mathrm{CaO}}{\mathrm{kg} \mathrm{GGBFS}}+423 \frac{\mathrm{kg} \mathrm{FA}}{\mathrm{m} 3 \mathrm{salt}} \times 13.2 \frac{\mathrm{g} \mathrm{CaO}}{\mathrm{kg} \mathrm{FA}}=226389.6 \frac{\mathrm{g} \mathrm{CaO}}{\mathrm{m} 3 \mathrm{salt}} \\
226389.6 \frac{\mathrm{g} \mathrm{CaO}}{\mathrm{m} 3 \mathrm{salt}} \times \frac{40.08 \mathrm{~g} \mathrm{Ca}}{56.0794 \mathrm{~g} \mathrm{CaO}}=161800.86 \frac{\mathrm{g} \mathrm{Ca}}{\mathrm{m} 3 \mathrm{salt}} \\
161800.86 \frac{\mathrm{g} \mathrm{Ca}}{\mathrm{m} 3 \mathrm{salt}} \times \frac{1}{1200} \frac{\mathrm{m} 3 \mathrm{salt}}{\mathrm{kg} \mathrm{dry}}=134.83 \frac{\mathrm{g} \mathrm{Ca}}{\mathrm{kg} \mathrm{dry}}
\end{gathered}
$$

For some elements (Al, S, Na, NO3/NO2), the contribution from the mixing solution must also be considered). Element available in each material are presented in the following Table 10.

Table 10 - Element available (g/kg dried material)

\begin{tabular}{lccc}
\hline Designation & Vault $\mathbf{1 / 4}$ & Vault $\mathbf{2}$ & Wasteform \\
\hline Calcium (Ca) & 72.42 & 48.22 & 134.83 \\
Silica (Si) & 24.85 & 37.66 & 162.70 \\
Aluminum (Al) & 5.88 & 11.16 & 69.25 \\
Iron (Fe) & 2.95 & 4.98 & 24.36 \\
Sulfur (S) & 1.05 & 0.59 & 3.08 \\
Magnesium (Mg) & 6.21 & 7.01 & 28.96 \\
\hline Potassium (K) & 0.80 & 1.73 & 9.98 \\
Sodium (Na) & 0.26 & 0.38 & 60.94 \\
Nitrogen (N) & 0.00 & 0.00 & 24.27 \\
\hline
\end{tabular}

\subsection{Sulfur profiles}

Sulfur content profiles were obtained by combustion and infrared dosage. Total sulfur profiles from Vault concrete mixes in contact with saltstone during 2 years are presented in Figure 8. On the plot, the position $\mathrm{x}=0$

${ }^{4}$ Abbreviations used: cem: cement, salt: saltstone, FA: fly ash 
correspond to the saltstone/concrete interface. Some data points for sulfur were also measured in the wasteform.

Sulfur profiles obtained are higher than the expected theoretical values (baselines). At this point, no satisfactory explanation for the discrepancy could be found. Experimental errors associated with the analytical procedure may be a possible explanation.

Despite this problem, measurements provide information on the sulfur diffusion through the interface. The profiles do not show any significant gradient. Although not perfectly horizontal, the profiles oscillate around what is seemingly a constant average value. The profiles suggest very limited transfer of sulfate from the saltstone to the concrete.

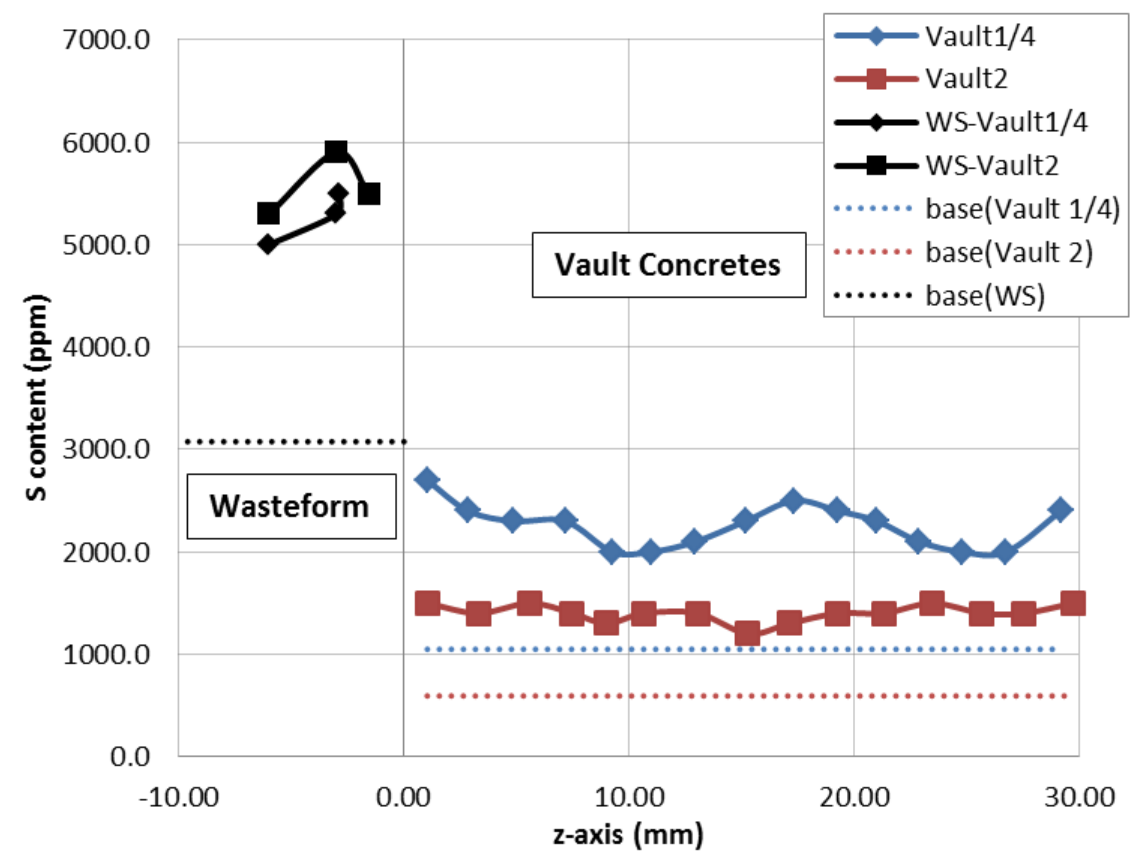

Figure 8 - Total sulfur profiles after 2 years

\subsection{Nitrate/nitrite profiles}

Nitrates and nitrites contents profiles were obtained by ion chromatography. Total nitrogen (N) profiles from nitrates and nitrites in Vault concretes exposed to Wasteform during 2 years are presented in Figure 9.

Results presented in Figure 9 show that species diffused from the wasteform slurry to vault concrete over the 2-year period. The profile is slightly lower in Vault 2 (56ppm at $7.50 \mathrm{~mm}$ depth) than Vault $1 / 4$ concrete (67ppm at 9.26mm depth), confirming better diffusivity properties in Vault 2 concrete (Protière and Samson, 2014b). Overall, the combination of low tortuosity for both layers contributed to limited mass exchange 
between materials, despite high concentration gradients. For nitrate/nitrate, the measurement showed a lot of variations. Only those data close to the theoretical values are plotted.

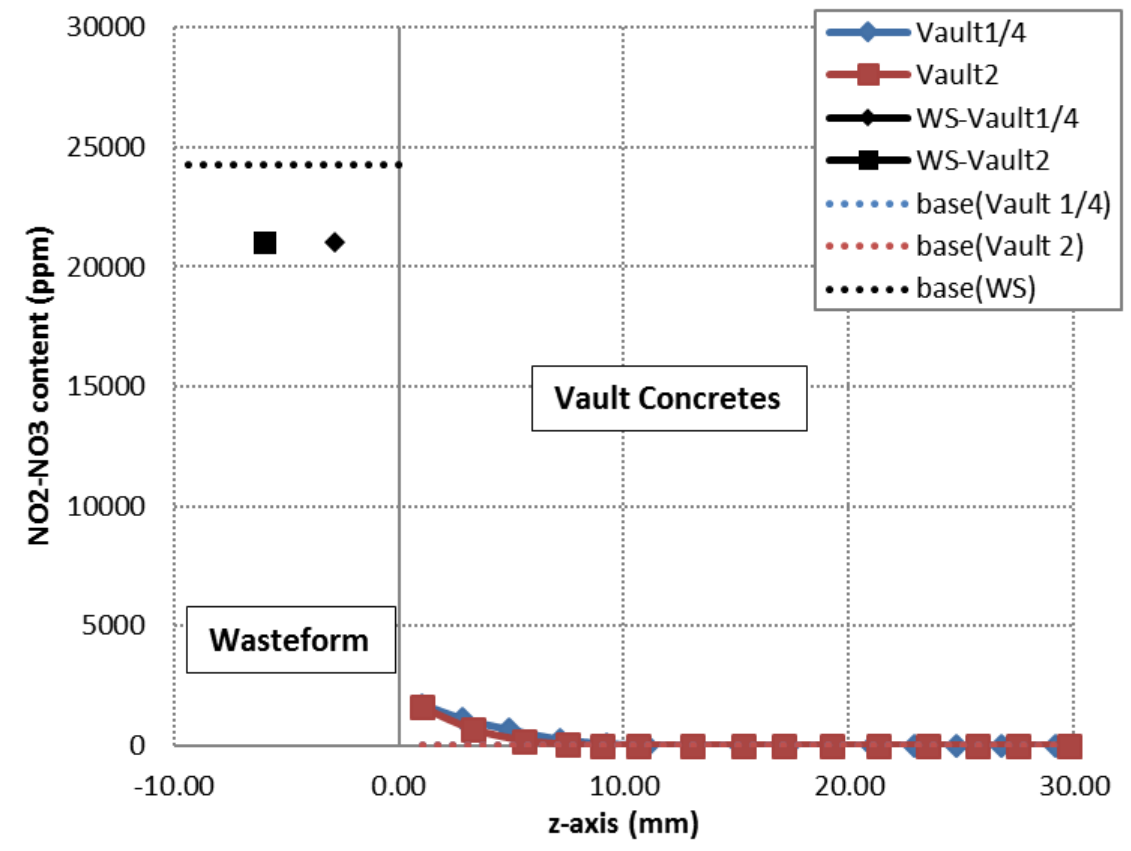

Figure 9 - Nitrate/Nitrite $(\mathrm{N})$ profiles after 2 years

\subsection{Main metals profiles}

Metal species (calcium, sodium, potassium, magnesium) profiles were obtained by Microwave Plasma-Atomic Emission Spectroscopy. The results are presented in the following figures. The only species that shows clear transfer from saltstone to concrete is sodium, which is the result of the large concentration gradient between layers. But similar to nitrate and nitrite, the diffusion of sodium is limited over a very short distance in concrete, which reflects the low diffusivity of the materials. 


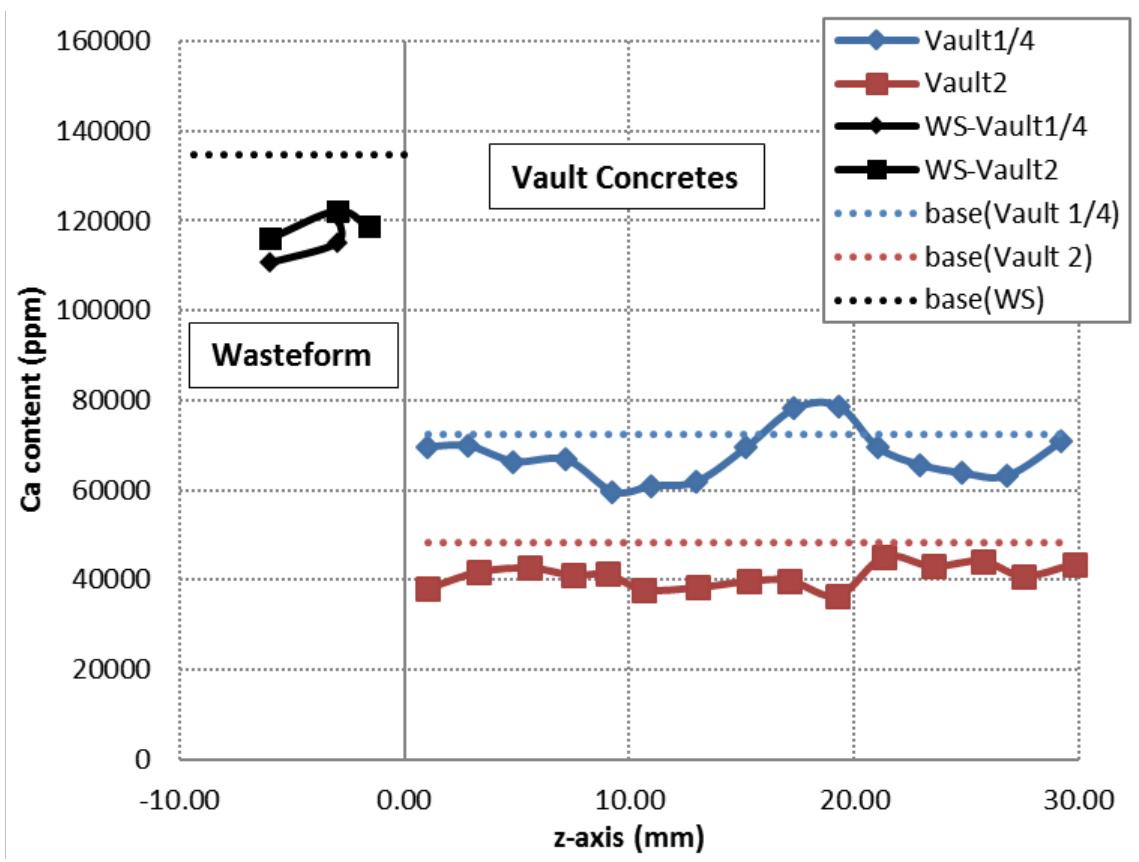

Figure 10 - Calcium (Ca) profiles after 2 years



Figure 11 - Potassium (K) profiles after 2 years 




Figure 12 - Sodium (Na) profiles after 2 years

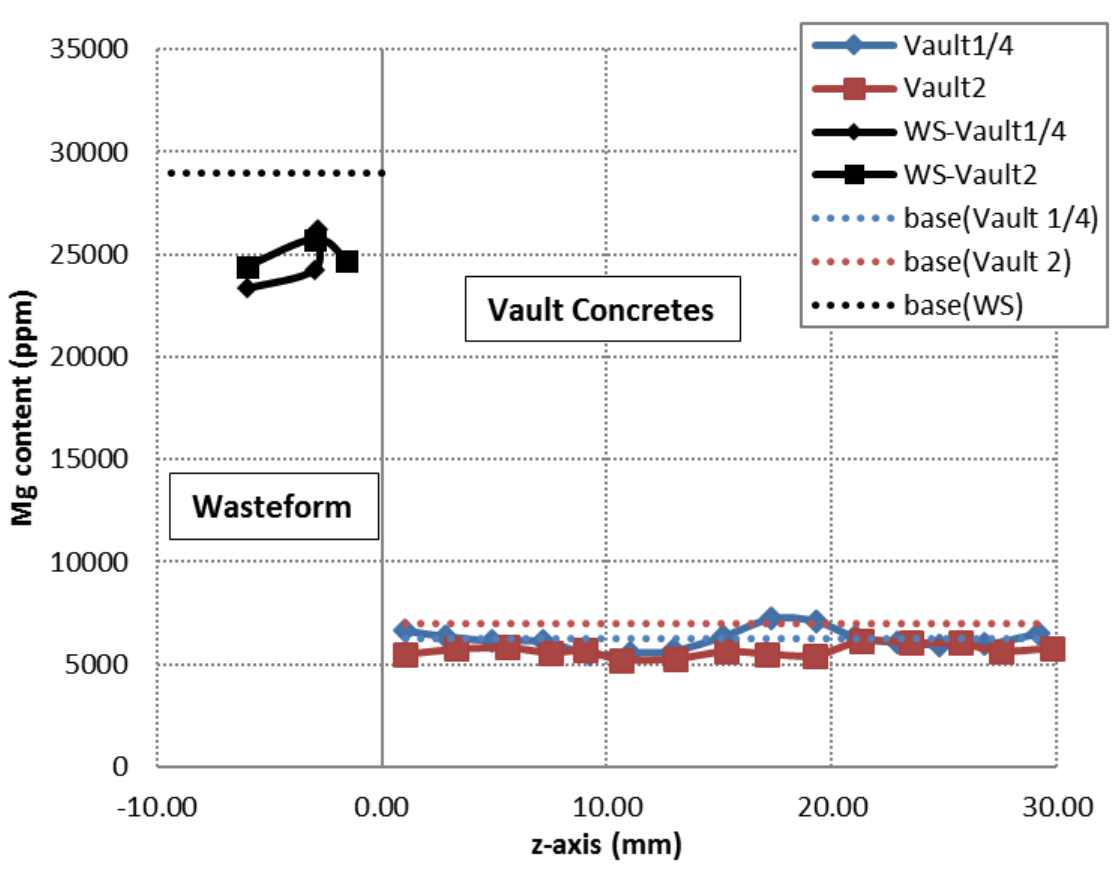

Figure 13 - Magnesium (Mg) profiles after 2 years 


\subsection{SEM/EDS observations}

A SEM microanalysis of Vault 2 concrete exposed to wasteform material during two years was performed. To get samples, 25-mm thick disks were cut from the concrete cylinders near the exposed surface (concrete/saltstone interface). The disks were then cut into four quarter. One quarter each for Vault $1 / 4$ and Vault 2 mixes were broken into pieces with a hammer to get a fresh surface. Pieces with a relatively flat surface were selected for SEM/EDS observations. Those samples were conditioned by applying a thin conductive coating made of gold (Au) and palladium (Pd) under vacuum by impinging electron beam.

The SEM apparatus was a JSM840A model (JEOL). The electron beam voltage was 15kV. Some Energydispersive X-ray spectroscopy (EDS) measurements were also performed with an Avalon model (PGT) equipped with a germanium detector.

Figure 14 presents a general overview of the Vault 2 concrete microstructure exposed to wasteform during two years. Air voids and some minor microcracking were observed in the concrete paste, as shown in the delimited area in the figure. However, these features were not observed elsewhere in the investigated samples and may have been created when the samples were prepared. Overall, the material did not exhibit the severe surface cracking that was observed in Vault 2 hydrated paste samples exposed to the $\mathrm{Na}_{2} \mathrm{SO}_{4} / \mathrm{NaOH} / \mathrm{NaNO}_{3}$ solution (CBP Report CBP-TR-2015-007, Rev. 1, see Figure 15). Clear signs of chemical degradation were absent from the samples.

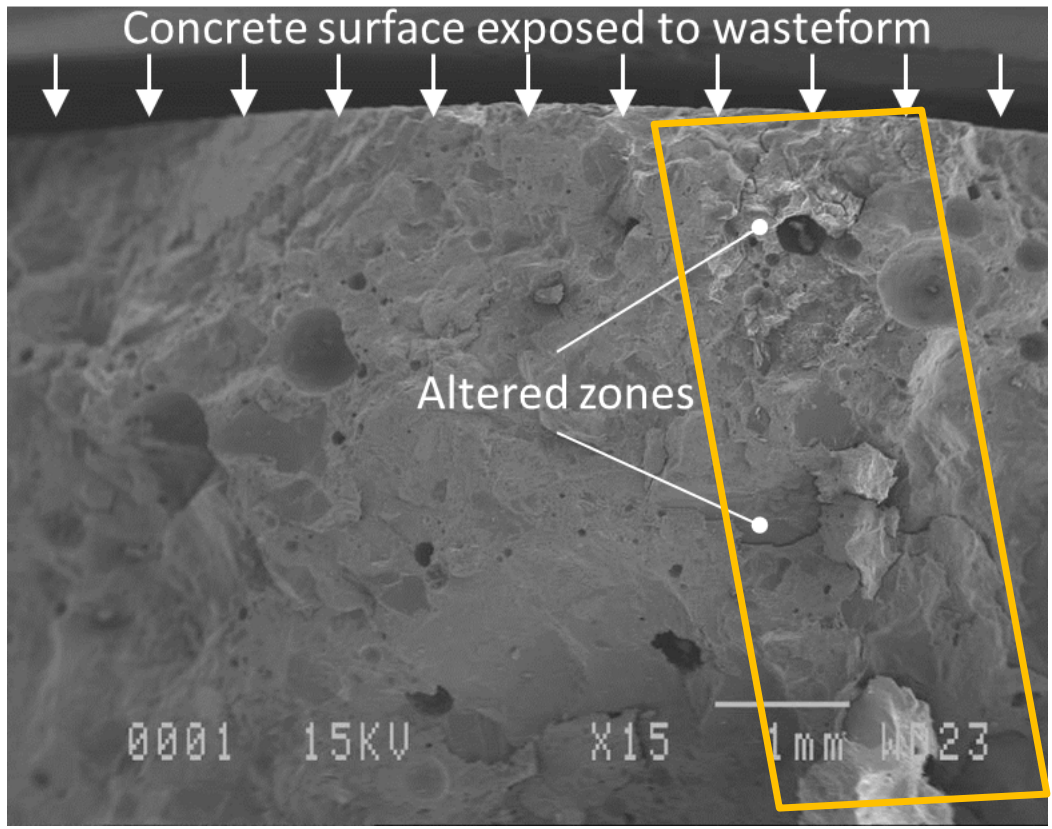

Figure 14 - SEM micrograph of Vault 2 concrete (x15) exposed to wasteform for 2 years

One possible explanation for the differences observed from the two test series is the lower contaminant ingress rate in the two-layer system, compared to hydrated paste samples directly immersed in aggressive solutions. 
As measured in section 5, the wasteform, despite its high porosity, has a very low tortuosity and diffusive properties. This means that species diffusing from the wasteform into the concrete are not immediately replenished but instead need some time to reach the interface between both layers. This translates into a less severe ingress rate, compared to the direct immersion case. This was observed in the sulfur measurements (Figure 8), which did not show significant sulfate ingress into the concrete.

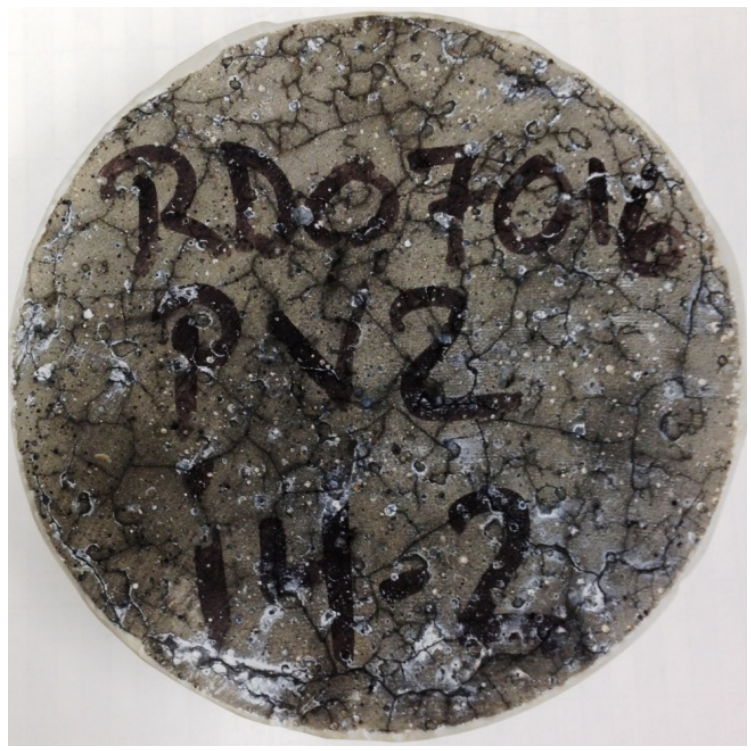

Figure 15 - Vault 2 hydrated paste exposed to $\mathrm{Na}_{2} \mathrm{SO}_{4} / \mathrm{NaOH} / \mathrm{NaNO}_{3}$ solution (from CBP-TR-2015-007, Rev. 1 report)

In order to identify phases formed in concrete microstructure due to the wasteform exposure, small air bubbles near the exposed surface of the Vault 2 concrete were observed using EDS. The observed sites were selected in the yellow area in Figure 14. Two air bubbles areas were selected; one is presented in Figure 16, and a second in Figure 17 and Figure 18. The Vault 2 concrete mix was selected due to the severe damages observed in paste samples based on the Vault 2 mix, as reported in CBP report CBP-TR-2015-007, Rev. 1.

Figure 16 shows a silica- and calcium-rich phase formed in an air bubble near the exposed surface. This phase has a fibrous appearance and fills a significant portion of the void volume. The solid phase also contains some sodium, alumina and possibly sulfur as secondary components. It was hypothesized that a silica-rich gel was the cause of severe degradation observed in hydrated pastes in CBP report CBP-TR-2015-007, Rev. 1. This siliceous phase may fit with this assumption, but more evidence is needed before this hypothesis can be confirmed. 


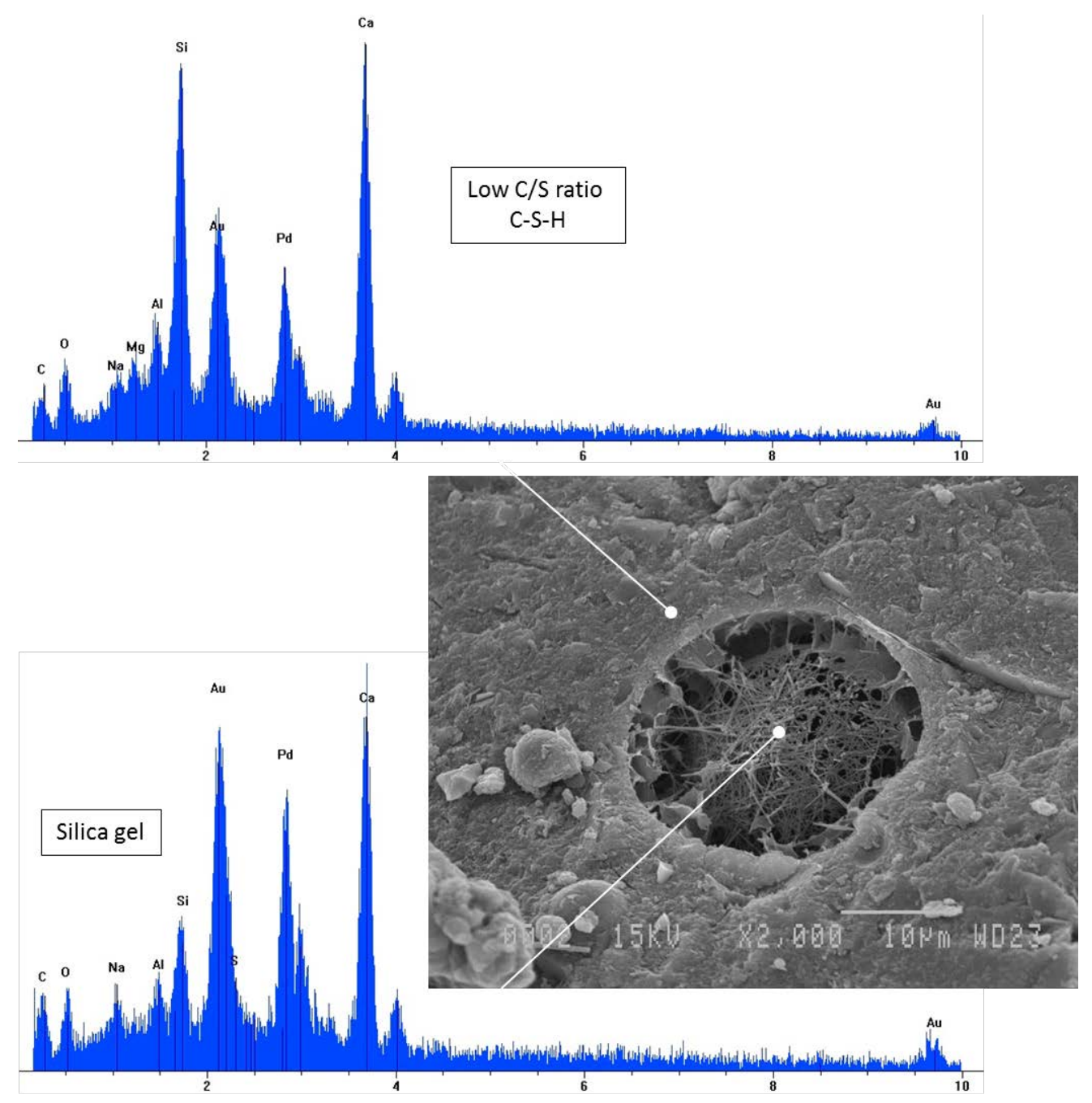

Figure 16 - SEM micrograph (x2000) and EDS analyses from Vault 2 concrete

Low C/S ratio C-S-H gel has also been identified around the air bubble. An EDS analysis identified calcium and silica as major components, and also some alumina and magnesium as secondary components, possibly as substitution in C-S-H. Replacing Portland cement with slag has been reported to reduce the C/S ratio (e.g. Richardson 1994).

Figure 17 shows another phase precipitated in a bubble near the exposed surface. This phase has a needleshaped crystals appearance associated with ettringite, and fills a significant fraction of the void volume. An EDS analysis identified calcium, sulfur and alumina as major components, which fits with ettringite composition. Low C/S ratio C-S-H gel has also been identified around this air bubble. As shown on Figure 18, the presence of unhydrated fly ash and slag was also detected around the bubble. 

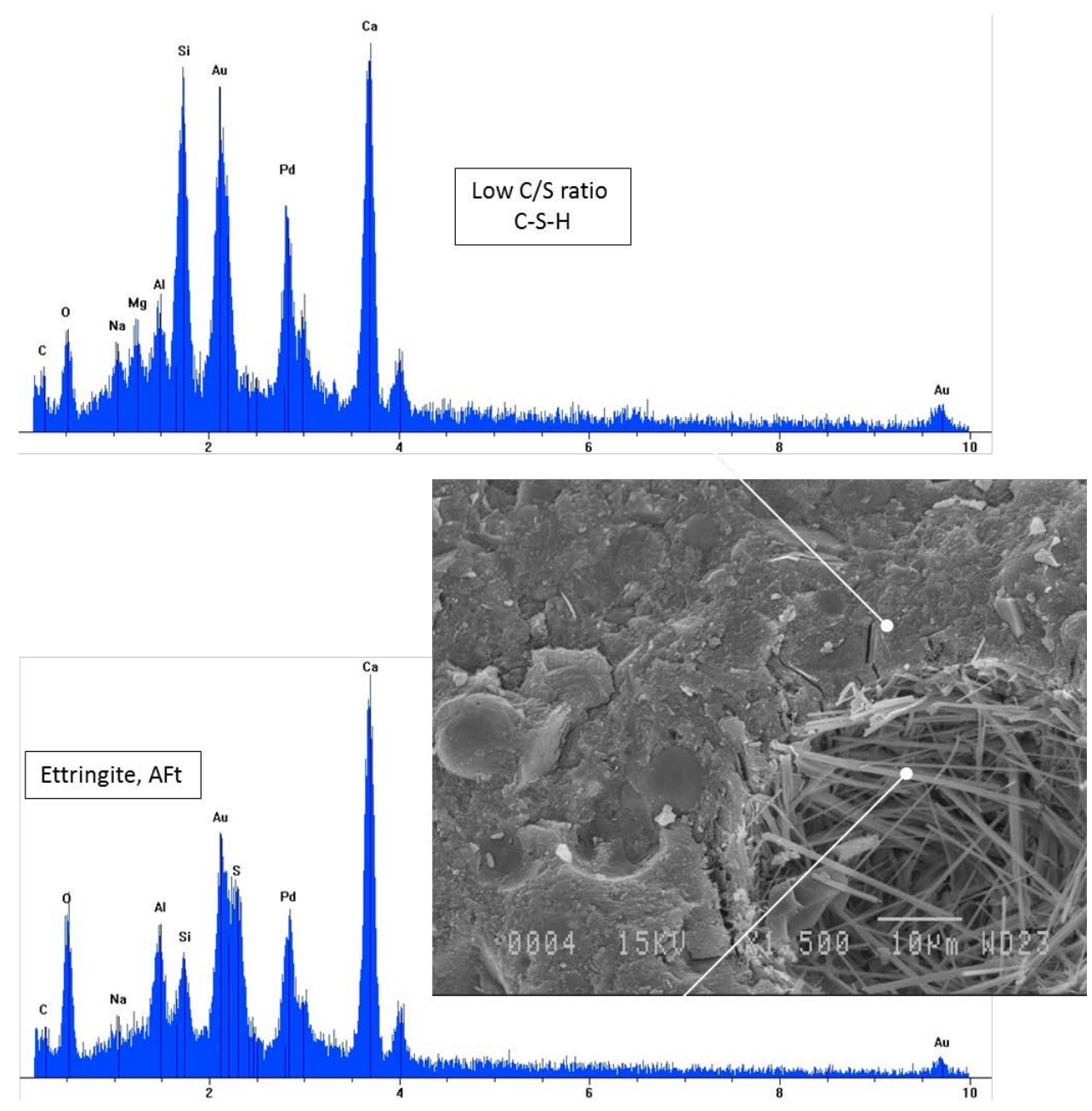

Figure 17 - SEM micrograph (x1500) and EDS analysis in a second air bubble from Vault 2 concrete 

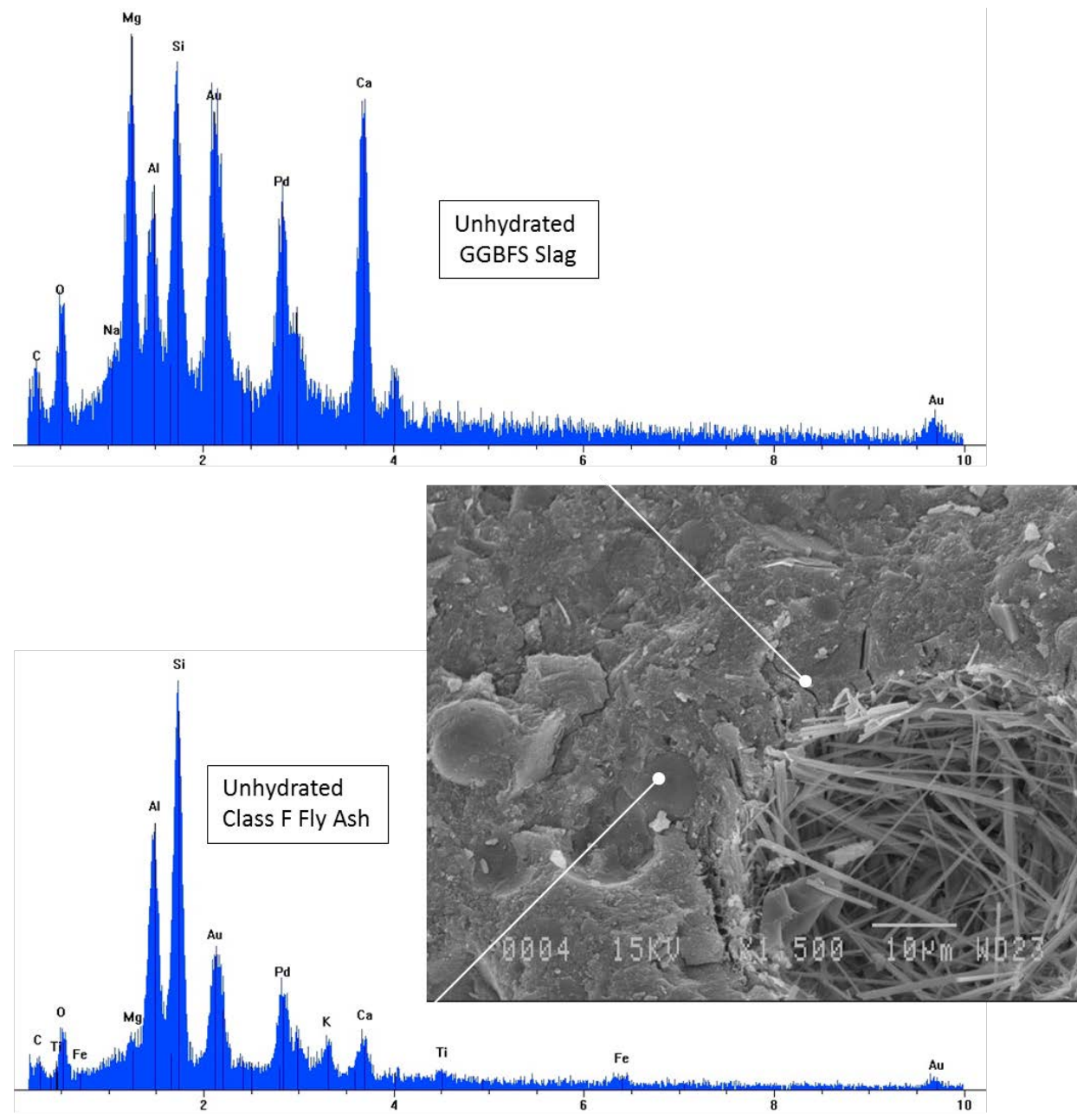

Figure 18 - SEM micrograph (x1500) and EDS analyses of unhydrated phases, from Vault 2 concrete 


\subsection{CONCLUSIONS}

The first portion of the study presented in this report focused on the characterization of transport properties of the saltstone mixture. Porosity and tortuosity were measured over a 2-year period, to assess the potential impact of hydration. Porosity measurements showed that the saltstone grout is very porous. The test results also showed that porosity did not vary with time after 28 days of curing.

Tortuosity and diffusion coefficient values were measured on the basis of the migration test procedure, where species transport is accelerated using applied electrical potential. The measurements showed a decrease in electrical current values between 28 and 91 days, but was stable after that. The reduction in current values was attributed to hydration of cementitious materials. Analysis of the current curves revealed that despite its high porosity, the material exhibits very low tortuosity. The tortuosity value of the saltstone is lower than the tortuosity measured on Vault 1/4 and Vault 2 concrete mixtures.

In the second portion of the experimental program, a setup was prepared which consisted of saltstone poured on top of Vault concrete mixes cured for approximately 6 months. The system was sealed to maintain saturated conditions throughout the duration of the test. After 2 years, the materials were separated. Upon separation, no signs of chemical degradation were observed. This contrasted with another study where hydrated paste samples with the same cement, slag, fly ash, and silica fume proportions as the Vault 2 mix were immersed in contact solutions with sulfate levels similar to those found in saltstone and showed alterations. One possible explanation for the absence of damage is the slow exchange rate between the saltstone and concrete, owing to the low tortuosity of saltstone.

Concrete samples were analyzed to quantify the extent of species that diffused from saltstone. Overall, only very concentrated species, such as sodium and nitrate/nitrite, showed clear sign of diffusing into concrete. Other species such as sulfate did not show significant ingress.

Limited SEM/EDS observations were also performed on the Vault 2 concrete near the saltstone interface. Although ettringite could be observed in air bubbles near the concrete/saltstone interface, the concrete paste did not show signs of damage. A silica gel was also observed in some air bubbles. It was hypothesized that a silica-rich gel was the cause of severe degradation observed in hydrated pastes from the previous study on hydrated pastes. This siliceous phase observed in the present study may fit with this assumption, but more evidence is needed before this hypothesis can be confirmed. 


\section{REFERENCES}

ASTM Standard C305 (2013) "Mechanical Mixing of Hydraulic Cement Pastes and Mortars of Plastic Consistency”, ASTM International, West Conshohocken, PA, USA.

ASTM Standard C642 (2013) "Standard Test Method for Density, Absorption, and Voids in Hardened Concrete, ASTM International, West Conshohocken, PA, USA.

ASTM Standard C1152 (2012) "Standard Test Method for Acid-Soluble Chloride in Mortar and Concrete", ASTM International, West Conshohocken, PA, USA.

ASTM Standard C938-10 (2010) "Standard Practice for proportioning grout mixture for preplaced-aggregate concrete”, ASTM International, West Conshohocken, PA, USA.

ASTM Standard C305-13 (2013) "Standard Practice for Mechanical Mixing of Hydraulic Cement Pastes and Mortars of Plastic Consistency”, ASTM International, West Conshohocken, PA, USA.

MA. 310 - CS 1.0, rev.3 (2013) "Determination of carbon and sulfur: method by combustion-infrared analysis and spectrophotometry” (French version), Ministère du développement durable, de l'Environnement, de la Faune et des Parcs du Québec, 2013, 8 p.

MA. 300 - Ions 1.3, rev.3 (2014) "Determination of anions by ion chromatography method" (French version), Ministère du Développement durable, de l'Environnement et de la Lutte contre les changements climatiques du Québec, 2014, 18 p.

Protière Y., Samson E. (2014a) “OPC paste samples exposed to aggressive solutions”, Cementitious Barriers Partnership Task 12 Report: CBP-TR-2015-001-C3.

Protière Y., Samson E. (2014b) “Concrete mixture characterization”, Cementitious Barriers Partnership Task 12 Report: CBP-TR-2015-003, Rev. 0.

Protière Y., Samson E. (2015) “SCM Paste Samples Exposed to Aggressive Solutions”, Cementitious Barriers Partnership Task 12 Report: CBP-TR-2015-007, Rev. 1.

Richardson I.G., Groves G.W. (1997) "The structure of the calcium silicate hydrate phases present in hardened pastes of white Portland cement/blast-furnace slag blends”, Journal of Material Science 32, 4793-4802.

Samson E., Marchand J. (2007a) Modeling the transport of ions in unsaturated cement-based materials, Computers and Structures 85, 1740-1756.

Samson E., Marchand J. (2007b) Modeling the effect of temperature on ionic transport in cementitious materials, Cement and Concrete Research 37, 455-468.

Samson E., Henocq P., Marchand J., Beauséjour P. (2008) "Recent advances in the determination of ionic diffusion coefficients using migration test results”, RILEM Proceedings 58-CONMOD 2008, E. Schlangen and G. de Schutter eds. (Delft, The Netherlands), pp. 65-78.

Taylor H.F.W. (1997) Cement Chemistry, Thomas Telford (London, UK), $2^{\text {nd }}$ edition. 


\section{A. Migration Test Analysis}

\section{Theoretical background}

The STADIUM ${ }^{\circledR}$ IDC laboratory module is used to analyze migration test results and estimate the diffusion coefficients of cementitious materials. It is based on the same mass transport model that powers the full version of STADIUM®.

The mathematical model has been described in several publications (see for instance Samson 2007a, Samson 2007b). Development specific to the migration test analysis has been presented in (Samson 2008). This chapter summarizes the model and its application to migration test analysis.

The model is based on a Sequential Non Iterative Algorithm (SNIA) that separately solves the transport equations and the chemical equilibrium relationships. The transport equations are discretized using the finite element (FE) method and solved simultaneously using a coupled algorithm. The calculation core begins a time step by solving the transport conservation equations without considering chemical reactions. When this step has converged, the chemical function analyzes each node of the FE mesh and makes sure that the pore solution concentrations and the mineral phases are in equilibrium. When this is completed, another time step starts.

There are four main components to the transport conservation equations: ionic transport, electrodiffusion potential, moisture transport and temperature (energy) conservation. Since migration tests are performed in constant temperature and saturated conditions, terms associated moisture transport and temperature gradients are neglected from the test analysis. The species mass conservation equation is written as:

$$
\rho \frac{\partial c_{i}^{b}}{\partial t}+\frac{\partial\left(\phi c_{i}\right)}{\partial t}-\operatorname{div}\left(D_{i} \phi \operatorname{grad}\left(c_{i}\right)+\frac{D_{i} z_{i} F \phi}{R T} c_{i} \operatorname{grad}(\psi)+D_{i} \phi c_{i} \operatorname{grad}\left(\ln \gamma_{i}\right)\right)=0
$$

where $c_{i}$ is the concentration of species $i[\mathrm{mmol} / \mathrm{L}], c_{i}^{b}$ is the amount bound as a result of physical interaction $[\mathrm{mol} / \mathrm{kg}], \phi$ is the porosity $\left[\mathrm{m}^{3} / \mathrm{m}^{3}\right], \rho$ is the density of the material $\left[\mathrm{kg} / \mathrm{m}^{3}\right], D_{i}$ is the diffusion coefficient $\left[\mathrm{m}^{2} / \mathrm{s}\right], z_{i}$ is the valence number of the ionic species $i, F$ is the Faraday constant $[96488.46 \mathrm{C} / \mathrm{mol}], \psi$ is the electrodiffusion potential [V], $R$ is the ideal gas constant $\left[8.3145 \mathrm{~J} / \mathrm{mol} /{ }^{\circ} \mathrm{K}\right], T$ is the temperature $\left[{ }^{\circ} \mathrm{K}\right]$, and $\gamma_{i}$ is the activity coefficient. One such equation must be solved for each ionic species considered. The activity coefficients in the model are evaluated on the basis of the Harvie, Moller and Weare (HMW) implementation of Pitzer's ion interaction model.

As mentioned previously, chemical reaction terms are absent from the transport equations because they are solved separately by the chemical module. However, terms are included in the previous equation to take into account the physical interaction between the paste and chloride due to double layer effects. The physical binding term was estimated from binding experiments performed on hydrated $\mathrm{C}_{3} \mathrm{~S}$ pastes exposed to different chloride concentrations. This term is zero for all ionic species except chloride, for which $c_{i}^{b}$ is given by:

$$
c_{\mathrm{Cl}}^{b}=\xi p c_{\mathrm{Cl}}^{u}
$$

where $\xi$ is a conversion factor involving the amount of C-S-H in the material that converts the isotherm estimated in units of [ $\left.\mathrm{mol}_{\mathrm{C}} / \mathrm{kg}_{\text {dry }}{ }_{\mathrm{C} 3 \mathrm{~S}}\right]$ into [mol$\left./ \mathrm{kg}_{\text {material }}\right]$, and $p$ and $u$ are fitting parameters. The binding experiments were performed at two different $\mathrm{pH}$ conditions: $\left[\mathrm{OH}^{-}\right]=40 \mathrm{mmol} / \mathrm{L}$ and $435 \mathrm{mmol} / \mathrm{L}$. A linear interpolation between these two hydroxide concentrations allows estimating the physical binding at any $\mathrm{pH}$. To balance the charges, a similar term but opposite in sign is applied to $\mathrm{OH}^{-}$. The electrodiffusion term in the 
species conservation equation is primarily responsible for maintaining the electroneutrality in the pore solution. Its role is to balance individual ionic mobility so that there is no net accumulation of charge at any location in the pore solution. This term also accounts for the driving force induced by the external potential applied during the migration test. To solve the diffusion potential, the ionic transport equations are coupled to Poisson's equation, which relates the potential in the material to the ionic profile distributions:

$$
\operatorname{div}\left(\tau_{s} \operatorname{grad}(\psi)\right)+\frac{F}{\varepsilon}\left(\sum_{i=1}^{N} z_{i} c_{i}\right)=0
$$

where $\varepsilon\left[6.9 \times 10^{-10} \mathrm{C} / \mathrm{V} / \mathrm{m}\right]$ is the permittivity of water, $\tau_{s}$ is the intrinsic tortuosity of the material and $N$ is the number of ionic species in the pore solution.

Chemical equilibrium calculations follow transport calculations to enforce the equilibrium between the pore solution and the solid matrix at each node of the FE mesh. This is achieved mainly by precipitating and/or dissolving minerals. It is assumed that the chemical reaction rates are faster than the transport rate, even under an externally applied potential. The validity of this assumption was emphasized in (Samson 2008)). The equilibrium of each phase is modeled according to:

$$
K_{m}=\prod_{i=1}^{N} c_{i}^{v_{m i}} \gamma_{i}^{v_{m i}} \quad \text { with } \quad m=1, \ldots, M
$$

where $M$ is the number of solid phases, $N$ is the number of ions, $K_{m}$ is the equilibrium constant (or solubility constant) of the solid $m, c_{i}$ is the concentration of the ionic species $i[\mathrm{mmol} / \mathrm{L}], \gamma_{i}$ is its chemical activity coefficient, and $v_{m i}$ is the stoichiometric coefficient of the ith ionic species in the $m$ th mineral. Similar to the transport equations, the chemical activity coefficients are calculated using Pitzer's interaction model. If the solution is not in equilibrium with the paste, solid phases are either dissolved or precipitated to restore equilibrium. The pore solution is thus adjusted to enforce the equilibrium relationships of the mineral phases. After the pore solution concentrations are modified, the solid phases are also corrected according to:

$$
S_{m}^{t}=S_{m}^{t-1}-\frac{\phi X_{m} \Gamma_{m}}{\rho}
$$

where $S_{m}$ is the amount of a given solid phase [g/kg of material], $t$ indicates the time step, $n$ is the molar mass of the solid $m[\mathrm{~g} / \mathrm{mol}]$, and $X_{m}$ represent the amount of a given solid phase that has to dissolve to reach equilibrium $\left[\mathrm{mol} / \mathrm{m}^{3}\right]$.

The penetration of chlorides in concrete structures leads to the formation of a chloride-AFm solid compound called the Friedel's salt, $3 \mathrm{CaO} \cdot \mathrm{Al}_{2} \mathrm{O}_{3} \cdot \mathrm{CaCl}_{2} \cdot 10 \mathrm{H}_{2} \mathrm{O}$. During migration tests, chloride interacts with the paste even though the externally applied potential significantly increases the ionic velocity in the pore solution. In STADIUM ${ }^{\circledR}$, Friedel's salt is not considered a pure phase but rather forms solid solutions with AFm phases: monosulfate and iron-based $\mathrm{C}_{4} \mathrm{FH}_{13}$. The equilibrium relationship for the solid solution is given by:

$$
K_{s S}=\frac{(\mathrm{Cl})^{2}}{\left(C_{s S}\right)^{2 /|z|}} \frac{\chi_{s s}}{\chi_{\text {Friedel }}} f_{s s}
$$


where $K_{\mathrm{ss}}$ is the equilibrium constant of the solid solution, $(\mathrm{Cl})$ is the activity of chloride in the pore solution $[\mathrm{mmol} / \mathrm{L}],\left(C_{\mathrm{ss}}\right)$ is the activity of the exchanging species in the AFm end-member [mmol/L], $z$ is the valence number of this species, $\chi$ represents the mole fraction of the solids [mol $/ \mathrm{kg}$ of material], and $f_{\mathrm{ss}}$ is a correction factor that accounts for the nonideality of the solid solution.

The diffusion coefficients in the mass conservation equation are expressed as:

$$
D_{i}=\tau_{s} D_{i}^{o}
$$

where $\tau_{s}$ is the intrinsic tortuosity of the material and $D_{i}^{o}$ is the self-diffusion coefficient of species $i\left[\mathrm{~m}^{2} / \mathrm{s}\right.$ ]. The self-diffusion coefficients are found in many textbooks and are constant. STADIUM ${ }^{\circledR}$ IDC performs iterations until it finds the tortuosity that allows reproducing the measured currents. The current $I$ [A] are calculated in the model as the sum of the ionic fluxes:

$$
I=S F \sum_{i=1}^{N} z_{i} j_{i}
$$

where $j_{i}\left[\mathrm{~mol} / \mathrm{m}^{2} / \mathrm{s}\right]$ is the ionic flux of species $i$, and $S\left[\mathrm{~m}^{2}\right]$ is the surface of the sample. The expression for the flux is:

$$
j_{i}=-D_{i} \phi \operatorname{grad}\left(c_{i}\right)-\frac{D_{i} z_{i} F \phi}{R T} c_{i} \operatorname{grad}(\psi)-D_{i} \phi c_{i} \operatorname{grad}\left(\ln \gamma_{i}\right)
$$

The next figure shows a typical result of IDC simulations:

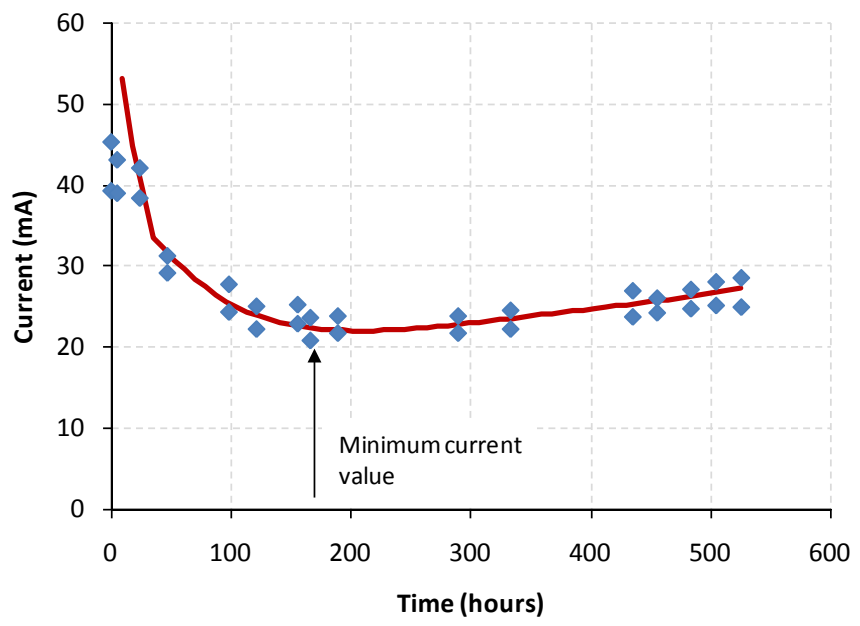

Figure 19 - Simulation of migration test measurements 0.45 w/c OPC mixture, ASTM Type I/II cement 


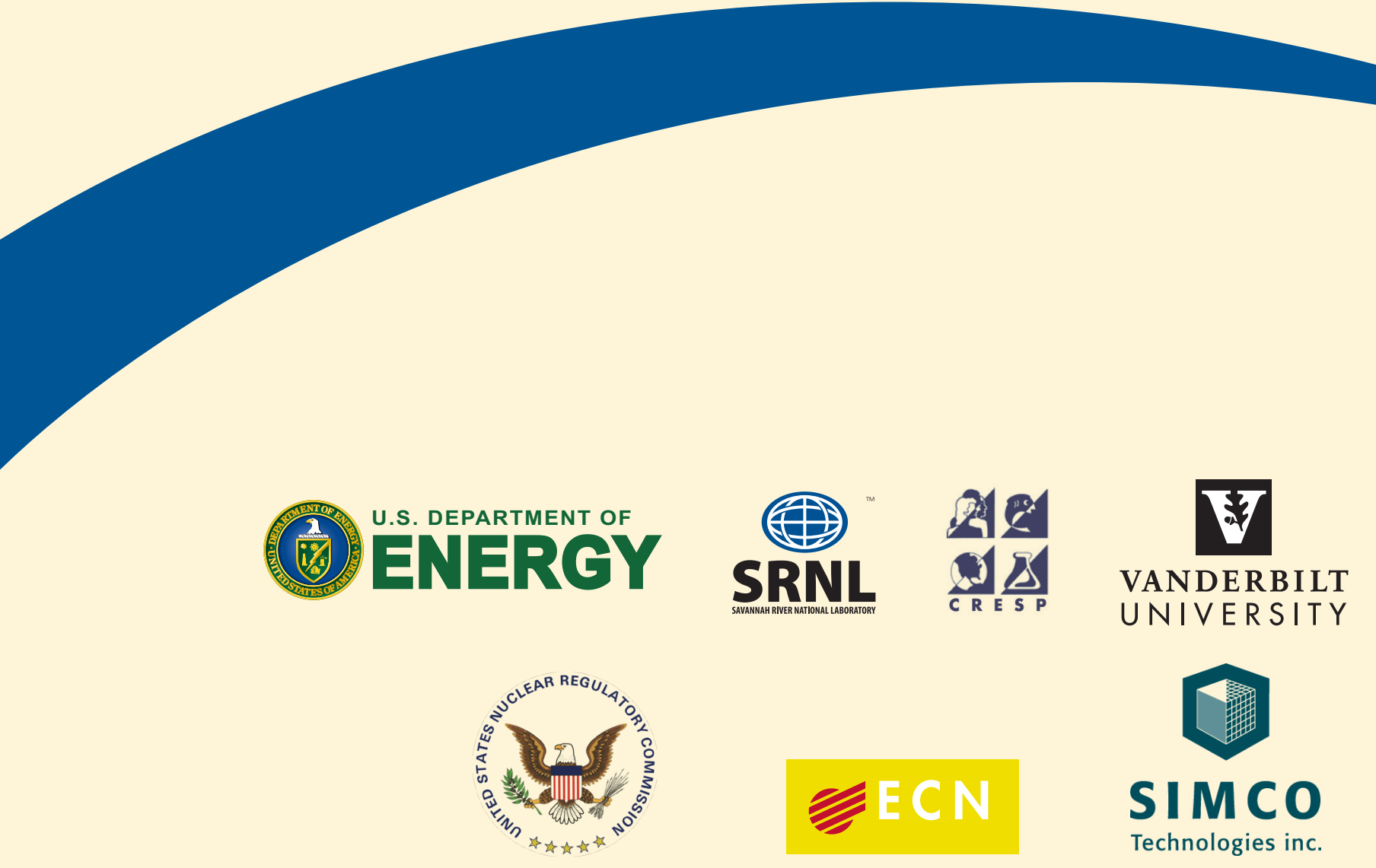

